To be published in Behavioral and Brain Sciences (in press)

(C) Cambridge University Press 2012

Below is the copyedited final draft of a BBS target article that has been accepted for publication. This updated preprint has been prepared for formally invited commentators. Please DO NOT write a commentary unless you have been formally invited.

\title{
Unconscious influences on decision making: A critical review
}

\section{Ben R. Newell}

School of Psychology, University of New South Wales, Sydney 2052, Australia. ben.newell@unsw.edu.au http://www2.psy.unsw.edu.au/Users/BNewell/Index.html

\section{David R. Shanks}

Division of Psychology and Language Sciences, University College London, 26 Bedford Way, London WC1H 0AP, England

d.shanks@ucl.ac.uk http://www.ucl.ac.uk/psychlangsci/research/CPB/people/cpb-staff/d_shanks

\begin{abstract}
To what extent do we know our own minds when making decisions? Variants of this question have preoccupied researchers in a wide range of domains, from mainstream experimental psychology (cognition, perception, social behavior) to cognitive neuroscience and behavioral economics. A pervasive view places a heavy explanatory burden on an intelligent cognitive unconscious, with many theories assigning causally effective roles to unconscious influences. This article presents a novel framework for evaluating these claims and reviews evidence from three major bodies of research in which unconscious factors have been studied: multiple-cue judgment, deliberation without attention, and decisions under uncertainty. Studies of priming (subliminal and primes-to-behavior) and the role of awareness in movement and perception (e.g., timing of willed actions, blindsight) are also given brief consideration. The review highlights that inadequate procedures for assessing awareness, failures to consider artifactual explanations of "landmark" results, and a tendency to uncritically accept conclusions that fit with our intuitions have all contributed to unconscious influences being ascribed inflated and erroneous explanatory power in theories of decision making. The review concludes by recommending that future research should focus on tasks in which participants' attention is diverted away from the experimenter's hypothesis, rather than the highly reflective tasks that are currently often employed.
\end{abstract}

Keywords: awareness; conscious; decision making; deliberation; intuition; judgment; perceptual-motor skills; unconscious 


\section{Introduction}

Psychology is concerned with understanding how the mind controls and determines behavior. Fundamental to this goal is whether unconscious influences play a significant role in the generation of decisions and the causation of behavior generally. Everyday notions such as "gut instinct" and "intuition" capture the idea that subtle influences falling outside awareness can bias behavior. Claims that "People possess a powerful, sophisticated, adaptive unconscious that is crucial for survival in the world" (Wilson 2002, p. vii) and that we should think less rather than more about complex decisions (Dijksterhuis et al. 2006) have a strong grip on both theoretical perspectives and the public imagination (e.g., Gigerenzer 2007; Gladwell 2005; Lehrer 2009). This article evaluates a wide range of research findings from the past 20 or so years that have contributed to the development of this perspective.

The unconscious has of course played a major role in the history of psychology, certainly predating Freud's extensive development of the concept. But in the past few years it has been the focus of extensive research in mainstream experimental psychology, including cognition, perception, and social behavior, as well as in cognitive neuroscience, behavioral economics, and other domains. Our focus is on the core process of decision making, which relates to all of these areas.

In this article we take decision making to refer to the mental processing that leads to the selection of one among several actions (choices). Construed this way, we exclude examples such as neurons or brain networks making "decisions". Thus the visual system's computation of low-level properties is not decision making on this definition. We view consciousness as a property of individuals and hence do not 
believe it serves any useful purpose to ask whether area V5's computation of motion, for instance, is or is not conscious. (It is, in contrast, perfectly reasonable to ask whether an individual's judgment of motion is conscious). ${ }^{1}$

The outline of the article is as follows: We begin by describing a framework for illustrating how unconscious processes could be causally effective in decision making (as defined above). We then articulate some of the requirements for an adequate test of awareness and discuss the legacy of Nisbett and Wilson's (1977) highly influential work. The body of the article reviews three major areas of research from the decisionmaking tradition in which unconscious factors have been studied: multiple-cue judgment, deliberation without attention, and decisions under uncertainty. A final section considers research from the priming literature, both subliminal priming and the so-called primes-to-behavior studies that are prevalent in social cognition (e.g., Bargh et al. 1996). Although few of these studies relate specifically to decision making, they are provocative illustrations of possible unconscious influences on behavior and thus warrant consideration in our review.

We do not, however, claim to offer a comprehensive literature review of all the research domains relevant to our guiding question. In particular, we only give very brief consideration (in section 6, Discussion) to the literature investigating awareness of decisions about movements (e.g., Libet 1985), illusory conscious will (e.g., Wegner 2004, and neuroscience phenomena such as blindsight (e.g., Weiskrantz 1986). Restricting our focus of course leaves us open to the criticism that we are "looking in the wrong place" for the evidence. Our response is twofold: First, pragmatic considerations make it impossible to consider all the evidence in a single article, but we contend that the areas we have selected have been highly influential in bolstering claims for unconscious decision making. Second, the areas we focus on in the core of 
the review are those that are most readily identified as involving decisions in the sense defined above. In the motor-movement and neuroscience domains, the nature of the decision being made and the information relied upon to make that decision are, arguably, less well defined in the first place, thus making discussions of peoples' awareness of them that much more difficult. We expand on these issues further in Section 6, the general discussion.

Our critical analysis points to a surprising conclusion, that there is little convincing evidence of unconscious influences on decision making in the areas we review, and that, as a consequence, such influences should not be assigned a prominent role in theories of decision making and related behaviors. This conclusion is consistent with the view that conscious thoughts are by far the primary driver of behavior (Baumeister et al. 2011) and that unconscious influences - if they exist at all - have limited and narrow effects.

\subsection{A framework for the components of decision making}

Our first step in examining the role of the unconscious in theories of decision making is to propose a framework for thinking about how decisions could be influenced by unconscious processes. The framework is based on the lens model (Brunswik 1952), popularized in the judgment and decision making field by Hammond, Stewart, and many others (for overviews, see Hammond \& Stewart 2001; Karelaia \& Hogarth 2008).

The basic premise of the lens model is that a decision maker views the world through a "lens of cues" that mediates between a stimulus in the environment and the internal perceptions of the decision maker, as shown in Figure 1. The double convex lens in the center of the diagram shows a constellation of cues that diverge from a criterion or event in the environment (left side of figure). The decision maker uses these cues to 
achieve (e.g., correctly estimate) the criterion, and so these cues are shown as converging (right side of figure) on a point of response or judgment in the mind of the decision maker. The lens model conceptualizes decision making as being guided by judgment (see note 1). An application of the lens model in the domain of medical diagnosis (e.g., Harries et al. 2000) would construe the physician as attempting to decide on the best treatment (the judgment) for a patient by determining the likelihood of a disease (the criterion) given the symptoms (cues) relied upon in making the judgment. 


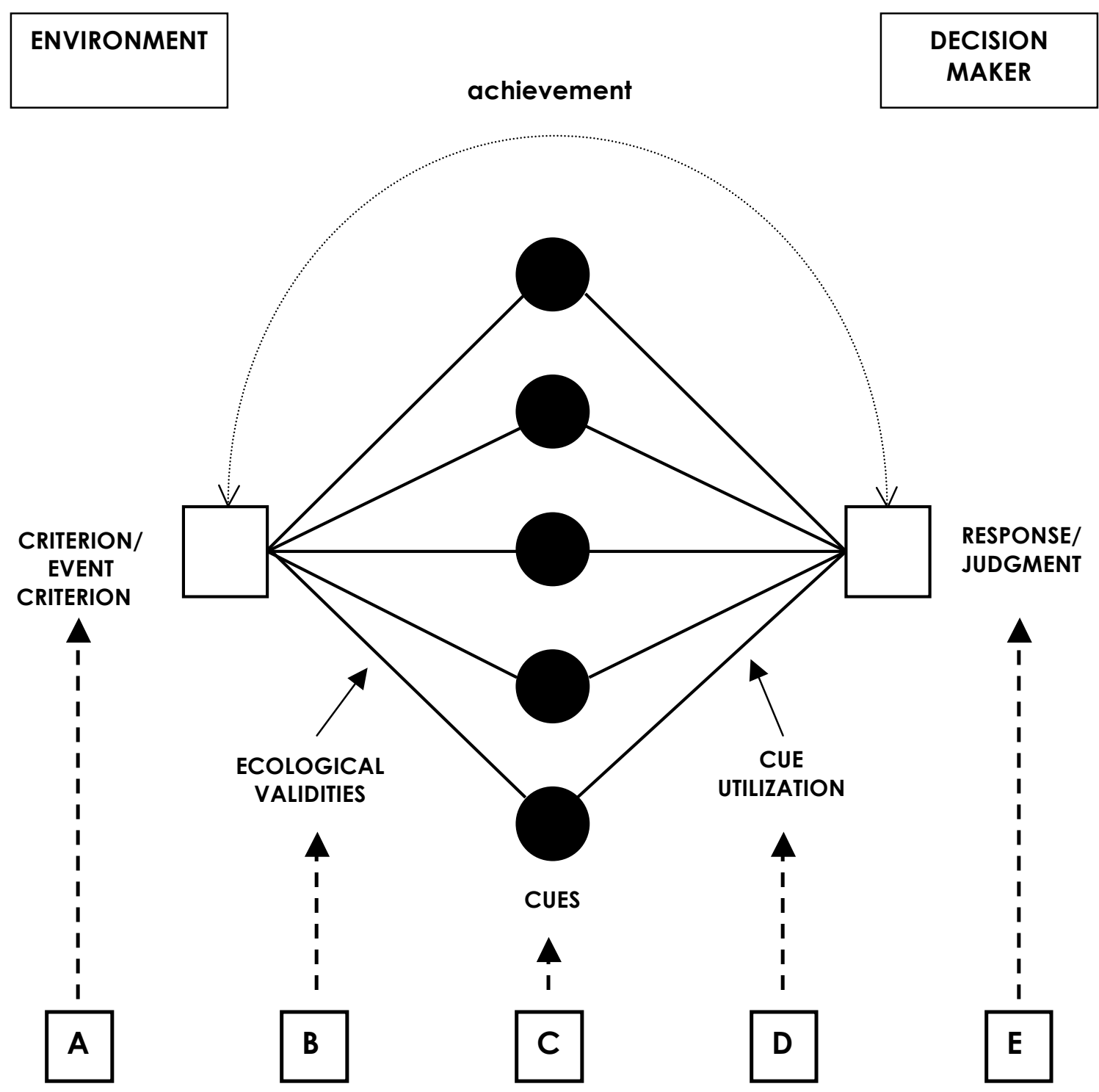

A decision-maker can be unaware of:

A: a criterion or event in the environment

B: environmental contingencies/relationships between cues and a criterion

C: the cues relied upon in making a decision

D: the weighting and integration of cue information

E: making a judgment

Figure 1. A lens model framework illustrating possible loci of unconscious influences on decision making. 
Figure 1 identifies five points (labeled A-E) at which an unconscious influence might be exerted on decisions. Point A captures the idea that an event or criterion in the environment that is not consciously perceived by the decision maker nonetheless influences behavior. An example might be lack of awareness of the feedback from making a correct or incorrect diagnosis. Point B is lack of awareness of contingencies or relations between consciously perceived cues and the criterion or outcome. The idea here is that there are properties of the stimulus environment (termed "ecological validities") that reliably predict a criterion, but that the individual might be unable to report or describe these relationships. For example, a doctor might be unaware that certain consciously perceived symptoms are predictive of an illness (e.g., Crandall \& Getchell-Reiter 1993). A lack of awareness of the cues relied upon to make a judgment or decision is illustrated by Point $\mathrm{C}$ in the figure. For example, a diner might be unaware that the relative position of an option on a menu influenced his choice (Dayan \& Bar-Hillel 2011); relative position in this scenario is simply not registered in consciousness. The difference between B and C is subtle: In one case (C) it is unawareness of a cue, whereas in the other (B) it is unawareness of the ecological or predictive validity of the cue. (Arguably, lack of awareness of a cue entails lack of awareness of its validity, hence cases of unawareness at $\mathrm{C}$ entail unawareness at B as well.)

Point D refers to a lack of awareness of one's utilization of cues. A doctor, for example, might appropriately base his or her diagnosis on features present in a mammogram, and might be aware of the features, but be unaware or mistaken about how he or she incorporates those features into his or her decision. The doctor might, for instance, be unaware of a complex non-linear rule he or she is tacitly employing to integrate information conveyed by the cues. Unawareness of cues (C) also entails 
unawareness of one's utilization (D) of those cues. Finally, Point E indicates lack of awareness of choosing or making a judgment. Consider a lawyer who uses the right of peremptory challenge against a potential juror, based on an unconscious judgment or stereotyping of the juror as racially biased.

Our use of the lens model as a framework is illustrative, and there are other formal frameworks such as signal detection theory and sequential analysis (see Gold \& Shadlen 2007) for conceptualizing the elements of decision making. ${ }^{2}$ Nonetheless, it affords some structure for evaluating the major areas of our review. Before turning to these areas, however, in the next section we outline a set of criteria that further help to evaluate possible unconscious influences on decision making.

\subsection{Criteria for the assessment of awareness}

Research on the role of awareness in decision making typically (but not invariably) seeks to contrast two types of measurement, one being some behavioral index of performance and the other being an awareness assessment based on the individual's report, verbal or otherwise. An unconscious influence on decision making is inferred if performance is affected by some cue or factor that is not reflected in awareness. Underlying theoretical constructs are not the same as the measurements that we take of them, and this is as true of awareness as it is of any other psychological construct. Hence it is essential to recognize that an assessment of awareness will only be informative if it is relatively free from bias and error.

The criteria that need to be met by adequate awareness measures have been the subject of extensive previous discussion (e.g., Dawson \& Reardon 1973; Ericsson \& Simon 1980; Lovibond \& Shanks 2002; Shanks \& St. John 1994). In brief, the more reliable, relevant, immediate, and sensitive an awareness assessment is, the less likely it is to be distorted by bias or error. Table 1 provides brief explanations of these 
criteria. As we shall see, many of these criteria are not met by studies claiming to show unconscious influences on behavior.

Table 1 Criteria for adequate assessments of awareness

\begin{tabular}{ll}
\hline Criterion & Explanation \\
\hline Reliability & Assessments should be unaffected by factors that do not \\
influence the behavioral measure (e.g., experimental demands, \\
social desirability). \\
Assessments should only target information relevant to the \\
behavior. \\
Assessments should be made concurrently (so long as they do \\
not influence the behavior) or as soon after the behavior as \\
possible to avoid forgetting and interference. \\
Assessment should be made under optimal retrieval conditions \\
(e.g., same cues are provided for measuring awareness as for \\
eliciting behavior).
\end{tabular}

The relevance criterion (called the "information" criterion by Shanks \& St. John 1994) merits further consideration. Although it may seem obvious that, in order to be suitable, an awareness assessment must target information that is relevant to the decision, experimental tasks often prompt violations of the criterion. A case in point arises in situations in which the researcher embeds a rule in the experimental 
materials and asks whether unconscious acquisition of this rule can influence behavior (see Fig. 1, Point B). Examples include artificial grammar learning (in which participants study strings of items that are constrained to follow certain transition rules (e.g., Pothos 2007) and invariant learning (in which structural relations govern the permissible stimuli). Much of the implicit learning literature is premised on the idea that participants can often respond on the basis of such rules without being able to describe them. It is very tempting for researchers to assume that participants' task performance must be based on an abstraction of the underlying rule governing the structure of the stimuli (e.g., Marcus et al. 1999). Yet numerous studies (e.g., Brooks \& Vokey 1991; Johnstone \& Shanks 2001; Newell \& Bright 2002) have documented how performance in these tasks can often be more appropriately explained via learning of entire stimulus configurations together with similarity-based decision making, or in terms of learning micro-rules. In such cases, the fact that participants may be unable to report the rule does not mean that it is unconsciously influencing behavior: To claim otherwise is to violate the relevance criterion.

A further issue in regard to the relevance criterion concerns the influence of distal versus proximal cues on decision making. ${ }^{3}$ The key issue is to what extent people are unaware of the information that is triggering their decision at the point of choice (proximal cues), as compared to information in the past (distal cues) that might have caused the current information (thoughts) to be present at the point of choice.

Consider a situation in which some distal cue (your mother advised you as a child that spinach is a good source of iron) caused a proximal cue (your current belief that spinach is healthy), which in turn influences a current decision (to select spinach off the menu). Even though you might be unaware of the distal influence on either your current belief or your decision, you might be perfectly able to justify your decision in 
terms of your proximal belief. Under such circumstances it is plainly inappropriate to claim that the decision is influenced by an unconscious factor.

There are, in summary, a number of important criteria that must be met in the design of an adequate awareness assessment (see Table 1). Although these requirements are extensive, it is important to note that the criteria are not unrealistic or unattainable. Some of the studies described at length below took considerable pains to deal with these issues of awareness measurement, by measuring awareness concurrently with performance (e.g., Lagnado et al. 2006) or via multiple convergent questions (Maia \& McClelland 2004) or by employing nonverbal performance measures assumed to index awareness (e.g., wagering: Persaud et al. 2007), using questions that are reliable, relevant, and sensitive. We do not believe that these criteria set the bar too high for assessing whether an influence is unconscious. The criteria do not force researchers to employ qualitatively different forms of assessment, merely to use standard ones in a more careful way with due recognition to the fine details of the experimental task and its demands.

\subsection{The legacy of Nisbett and Wilson}

To a considerable extent, the willingness of contemporary experimental psychologists to embrace the possibility of unconscious influences on behavior can be traced to the highly influential work of Nisbett and Wilson (1977). Nisbett and Wilson launched a powerful series of arguments that people typically lack insight into their own mental processes. Key among their claims were (a) that people often misreport causal influences on their behavior, falsely reporting factors that did not in fact influence their performance and failing to acknowledge factors that truly were causal, and (b) that people are rarely any more accurate in explaining their own behavior than outside observers are, prompting the famous conclusion that "if the reports of subjects do not 
differ from the reports of observers, then it is unnecessary to assume that the former are drawing on 'a fount of privileged knowledge"' (Nisbett \& Wilson 1977, p. 248). When people do give veridical reports, it is because they make use of a priori implicit theories about causal relationships between stimuli and responses, rather than because they have privileged conscious access to their own mental processes.

We will not extensively review the evidence that has accumulated on these issues since Nisbett and Wilson's (1977) article was published (for relevant discussions, see Adair \& Spinner 1981; Ericsson \& Simon 1980; Smith \& Miller 1978; White 1980; 1988). However, we will mention two significant challenges to Nisbett and Wilson's (1977) viewpoint. First, a number of their demonstrations under (a) above fail to meet our criteria regarding adequate assessments of awareness (see Table 1). Consider an experiment in which participants chose between (and justified their choice from) four consumer products that were in reality identical. Nisbett and Wilson (1977; more details of the original experiments are given in Wilson \& Nisbett 1978) found that participants tended to select the right-most of four alternatives (e.g., pairs of stockings) but did not mention position when justifying their choice, or flatly denied being influenced by position when asked directly (this would be an example of unawareness located at Point $\mathrm{C}$ in the lens model of Fig. 1). Instead, participants mentioned attributes such as the quality of the stockings. The problem with this finding is that asking participants about position fails the relevance criterion, as position is almost certainly not a proximal cause of choice (this argument was originally made by Smith \& Miller 1978). It is at best a distal cause, whose influence is mediated via the participant's true decision rule.

In such sequential choice situations, people tend to study the options one at a time, usually (but depending on culture) from left to right (Wilson \& Nisbett [1978] 
confirmed that this was the case in the experiment). Suppose that the decision rule is that if the current item is no worse in terms of quality than the previous item, then prefer the current item. After the initial item, each subsequent one is mentally compared with its predecessor (Li \& Epley 2009; Mantonakis et al. 2009), and because the items are identical, the resulting final choice is the right-most pair of stockings. Even though the rule may lead (wrongly) to the belief that one item is superior to the others, the choice is in no sense determined by spatial position. Spatial position only has an influence insofar as it affects how the items are sequentially sampled. Indeed, under such circumstances it is perfectly correct for participants to report quality as the basis of their decision, as their decision rule incorporates judgments of quality, and to deny being influenced by position. To establish that the choice is being driven by unconscious influences, it would be necessary to show that participants deny employing a sequential comparison process, but this is not what Nisbett and Wilson (1977) asked their participants. Claiming that their participants were unconsciously influenced by position is like claiming that an individual who chooses the apartment he or she saw on Thursday, after seeing others on Monday, Tuesday, and Wednesday, is unconsciously influenced in his or her choice by the day of the week. ${ }^{4}$

The second way in which subsequent research challenges Nisbett and Wilson's (1977) position is equally damaging. It appears far too strong to claim that observers who have access to nothing more than the public features of the stimuli and context can predict individuals' responses, as well as that those responses can be predicted by the individuals' own verbal reports on their mental processes. Apart from raising a number of serious methodological problems with Nisbett and Wilson's original studies (e.g., Guerin \& Innes 1981; Smith \& Miller 1978; White 1980), later research 
has clearly shown predictive advantages for actors over observers (Gavanski \& Hoffman 1987; White 1989; Wright \& Rip 1981). It is apparent that in many of the sorts of situations cited by Nisbett and Wilson, we do in fact have introspective access to our conscious mental states, and the verbal reporting of these states conveys privileged information about the causes of our behavior.

Having provided a framework for thinking about how unconscious processes might influence decisions, and having articulated some of the requirements for an adequate test of awareness, we now turn to three major areas in which unconscious factors have played a prominent role.

\section{Unconscious influences in multiple-cue judgment}

Research into multiple-cue judgment focuses on situations in which people attempt to predict an environmental criterion on the basis of imperfect probabilistic indicators just as a doctor might try to diagnose a disease on the basis of symptoms, medical history, and results of diagnostic tests. A long-standing question in this field is the extent to which such judgments are based on explicitly available knowledge. This question is of psychological importance because if "experts lack self-insight into the processes underlying these judgments, they may be unconsciously biased" (Evans et al. 2003, p. 608). This section investigates this claim first by reviewing evidence relating to the development of self-insight in novices learning experimental multicue judgment tasks, and second by examining the literature on the self-insight of experts performing real-world multiple-cue judgments.

Following the pioneering work of Hammond and colleagues (see Hammond \& Stewart 2001), many studies in this area have employed the lens model framework of Figure 1 to examine judgment. In a standard study participants make judgments about a series of "cases" (e.g., patients) for which information is available from a set of 
cues. Multiple linear regressions are then performed from the judgments to the cues to measure the "policies" that judges adopt. The beta weights obtained from these regressions give an indication of the cues that influenced the judge, as well as the relative extent of this influence. These beta weights are described as the implicit or tacit policy underlying judgment (indicated on Fig. 1, Point D, as cue utilizations). To examine the extent of insight into judgments, these implicit policies are then compared with self-assessments of the importance of cues for determining judgments. Importance can be assessed in a variety of ways, such as asking judges to divide 100 points between the cues, with higher numbers indicating greater reliance on a cue. The strength of the correlation between these ratings of importance and the beta weights derived from multiple regression is taken as indicating the extent of insight. A widely accepted consensus from this research is that there is often a lack of correlation between the two measures of the usage of cues, reflecting judges' poor insight (Arkes 1981; Evans et al. 2003; Slovic \& Lichtenstein 1971).

\subsection{Examining insight in novice judges}

According to some researchers, the reason for this poor insight is that judges learn how to make their judgments in an implicit manner (e.g., Evans et al. 2003), and these processes are thus inaccessible to introspection. Testing such an account in established experts is of course difficult because the relevant learning has already been accomplished. Thus researchers have studied the acquisition of judgment policies in laboratory analogues of typical real-world judgment tasks.

An illustrative study is that of Evans et al. (2003) who asked participants to predict the suitability of fictional job candidates for an unspecified job on the basis of "ability tests." The complexity of the task was manipulated by varying the ratio of relevant and irrelevant ability tests. Relevant tests contributed a constant value $(+1$ or -1$)$ to 
the linear model that determined feedback; irrelevant tests contributed zero.

Participants learned over a period of 80-100 trials with corrective feedback and were then given 40 test trials in which no feedback was provided. At the end of the test, participants rated each test on a scale from 1 (less relevant) to 7 (more relevant).

Evans et al. (2003) assessed "implicit” knowledge by measuring participants' revealed beta weights from test judgments and "explicit" knowledge by calculating a difference score between ratings given to relevant and irrelevant cues. In their second experiment, Evans et al. claimed to find a dissociation between these two measures of knowledge. Cue polarity (positive/negative) and absolute cue number (4 or 6) had large effects on the self-insight and performance scores (correlations between the criterion and prediction - labeled "achievement" in Fig. 1) but no effect on the explicit knowledge scores. Moreover, the difference between ratings for relevant and irrelevant predictors only differed from zero for one of three prediction tasks. This pattern of results led Evans et al. to conclude: "we have compelling evidence that performance ... was largely mediated by implicit learning” (p. 615).

There are, however, reasons to question such a strong conclusion. Participants were faced with different job tasks in each experimental session, each one involving a different relevant/irrelevant cue ratio and different numbers of positive and negative predictors. Self-ratings of cue relevance were made at the end of each task, thereby failing the immediacy criterion for assessment (see Table 1). The sensitivity of the measures can also be questioned: There were 40 intervening test trials without feedback before ratings were made, and there were three different tasks per session, all with common labels for cues (A-F). Both of these factors could have increased the chance for cross-task confusion, making the low levels of explicit knowledge rather unsurprising. 
In a recent study Rolison et al. (2011) used similar methods to investigate the role of working memory capacity (WMC) in multicue judgment. They found that WMC correlated with performance when tasks involved negative predictors, but not when all relevant cues were positive predictors. Rolison et al. interpreted this pattern as evidence for reliance on deliberative processes in tasks with negative cues, and on implicit processes in tasks with exclusively positive cues. However, their data also showed the same associations and lack of associations between WMC and explicit knowledge of the underlying task structure. Thus a plausible alternative explanation is that performance was mediated by explicit knowledge in all tasks, but that the latter sometimes is and sometimes is not related to WMC.

Taken together, these illustrative experiments provide little evidence that unconscious processes influence multicue judgment. The dominant pattern across the experiments in both the Evans et al. (2003) and Rolison et al. (2011) studies was of significant positive correlations between measures of performance and explicit knowledge of cue relevance/usage. In those instances where such correlations were absent, procedural artifacts (e.g., timing of awareness assessment) may have been responsible. In recognition of the problems of retrospective interrogation of explicit knowledge, Lagnado et al. (2006) used an approach in which participants learning a multiple-cue judgment task were probed throughout training trials for the explicit basis of each prediction. On each trial participants were asked to rate how much they had relied on each cue in making their prediction. The "explicit" cue ratings were then compared with the "implicit" weights derived from running "rolling" regressions (a series of regressions from predictions to cues across a moving window of consecutive trials; cf. Kelley \& Friedman 2002). 
The take-home message from the analysis of these data was that participants clearly distinguished between strong and weak predictors on both the implicit and explicit measures of cue reliance. This ability occurred fairly early in the task and was maintained or increased across training. Lagnado et al. (2006) also reported strong positive correlations between individuals' cue reliance ratings and implicit regression weights. The overall pattern strongly suggested that people had access to the internal states underlying their behavior and that this access drove both on-line predictions and explicit reliance ratings. Note that it is unlikely that the requirement to make on-line ratings altered participants' judgment strategies, as an additional experiment demonstrated that overall accuracy in the task was unaffected by the inclusion of the on-line ratings. In a recent study, Speekenbrink and Shanks (2010) extended this approach by using a "dynamic lens model” to assess participants' insight in an environment in which cue validities changed across the course of an experiment. Consistent with Lagnado et al. (2006), Speekenbrink and Shanks found little evidence for the contribution of implicit processes: Participants learned to adapt to changes in the environment, and their reports of how they changed their reliance on cues reflected their actual reliance on those cues as evidenced by their predictions.

\subsection{Assessing expert knowledge}

Much of the work examining expert judgment has focused on the necessary antecedent conditions for the development of "intuitive" expertise (e.g., Hogarth 2001; Kahneman \& Klein 2009; Shanteau 1992) and the relative accuracy of expert and statistical judgment (Dawes et al. 1989; Meehl 1954; Vrieze \& Grove 2009). Our focus here is somewhat different; we are interested in the rather smaller literature that has examined the extent and nature of experts' self-insight into the cues they use in real-world judgment tasks. 
Slovic and Lichtenstein (1971) were early to note that there were "serious discrepancies" (p. 49) between the explicit weights provided post hoc by judges and the implicit weights they placed on cues as evidenced by regression modeling. One source of this discrepancy was judges' tendency to overestimate the importance placed on minor cues and to underestimate their reliance on major cues. For example, Slovic et al. (1972) reported a correlation of only 0.34 between the implicit and explicit weights of 13 professional stockbrokers performing a stock selection task. The low correlation was attributed to the variance of explicit weights across the individuals: Each of the eight predictor variables was rated as most important by at least one judge, and some variables were rated subjectively more important than the regression analysis warranted.

The "serious discrepancies" identified by Slovic et al. (1972) and many others (e.g., Balzer et al. 1983; Phelps \& Shanteau 1978) seem problematic for the view that we have access to the information influencing our behavior. These results would seem to suggest that there are indeed unconscious influences on the process of weighting and integrating cue information (see Fig. 1, Point D). However, the strength with which such conclusions can be drawn depends crucially on the methods used to elicit the importance ratings. It is quite possible that judges have good insight, but that experimenters have not provided them with sufficient opportunities to report the knowledge that they possess. It is also possible that judges confuse questions about the "importance" of cues for the task environment (i.e., ecological validities; see Fig. 1, Point B) with their "importance" for their own judgment process (i.e., cue utilizations; see Fig. 1, Point D) (cf. Lagnado et al. 2006; Speekenbrink \& Shanks 2010; Surber 1985). As we shall see, there is considerable justification for these concerns. 


\section{$<\mathrm{B}>2.3$ Insight through policy recognition}

In an influential brace of articles, Reilly and Doherty $(1989 ; 1992)$ examined an alternative way of assessing insight and drew significantly more optimistic conclusions about experts' knowledge of their judgment policies. Their novel procedure used a policy selection or "recognition" test that involved identifying one's own policy (described by normalized cue utilization indices) from an array of possible policies. In both articles, across a variety of hypothetical judgment tasks, this policy recognition method of assessing insight revealed much higher levels of self-insight into implicit and explicit policy profiles than indicated in previous research.

Harries et al. (2000) extended the policy recognition approach by assessing selfinsight in medical general practitioners. The doctors had taken part in a policycapturing study 10 months prior to the insight assessment. They had been asked to make prescription decisions (e.g., whether to prescribe lipid-lowering drugs) for 130 hypothetical patients, each described by 13 cues (e.g., hypertension, cholesterol level, age), and to rate the importance of each cue for their judgments. In the follow-up, the doctors were presented with two arrays each containing 12 bar charts. The first array displayed implicit policy profiles (regression weights), and the second explicit profiles (importance ratings) both on standard bar charts. The 12 charts included the participant's own policy and 11 others randomly selected from the total pool of 32 participants. Their task was to rank the three policies in each set that they thought were closest to their own.

Consistent with Reilly and Doherty $(1989 ; 1992)$, the doctors were significantly above chance at picking both types of policies. The average hit rate (having one's own policy in the three selected) was 0.48 for implicit and 0.50 for explicit policy recognition. This level of performance is clearly far from perfect but it is considerably 
better than the 0.25 hit rate expected by chance. This replication is important because it not only demonstrates self-insight in genuine domain experts (instead of undergraduate students), but also rules out one possible explanation for Reilly and Doherty's findings. In their study some participants mentioned selecting explicit policies on the basis of explicit memory for the particular numbers of points they had distributed to individual cues (e.g., "I know I used 2.5 for one attribute"). Such memory for specifics, rather than insight into the actual policy, is less likely to have been a contributing factor in the Harries et al. (2000) study, given that policy recognition was conducted 10 months after the judgment task and importance ratings were represented as bar charts. Note that although the tests used in these studies do not meet the immediacy criterion for awareness assessment (see Table 1), the use of recognition rather than free recall makes it a more sensitive and arguably relevant test of insight.

The recognition measures used in the Reilly and Doherty studies revealed an “astonishing degree of insight” (Reilly \& Doherty 1989, p. 125), but the standard measures (e.g., correlations between implicit and explicit policy weights) showed the same poor to moderate levels as seen in many previous experiments. Furthermore, in both studies predictions on hold-out samples of judgments (i.e., cross-validation) demonstrated that models using implicit weights were superior to those using explicit weights in almost $100 \%$ of cases. Thus there appears to be "something else" captured in the implicit policies that participants are unable to communicate in their explicit policies.

However, the lower predictive accuracy of explicit weights and the tendency for people to state that they have relied on more cues than are apparent from their judgments (e.g., Slovic et al. 1972) might also be partially artifactual. Harries et al. 
(2000) pointed out that explicit weight estimates are based on a sample size of one that is, they are made once, at the end of a series of (often) hundreds of judgments. As such they fail the immediacy, sensitivity, and reliability criteria for awareness outlined in Table 1. In contrast, the implicit weights are calculated from all trials and are thus more likely to capture patterns of cue use. Thus the low correlation between the two types may be due to the weakness of the cue importance measure.

The mismatch between stated and actual cue use could also be attributable to another aspect of typical experimental designs: the use of orthogonal cue sets (cf., Harries et al. 2000; Reilly \& Doherty 1992). Policy-capturing studies aim to discover reliance on particular cues; this is very difficult to do if a stimulus set contains highly intercorrelated cues, and so experimenters take pains to develop orthogonal cue sets. However, this can lead to problems if a judge uses cues inconsistently across cases. Harries et al. (2000) cited the example of a doctor using overweight or blood pressure interchangeably in making a decision about hypertension (because the two cues are highly correlated in reality). If the doctor was then presented with hypothetical cases in which these cues were orthogonal, he or she might still switch between them in his or her judgments but rate them both highly important at the end of the task. The regression analysis would then reveal equal but only moderate reliance on the cues, which would mismatch with the high importance ratings. In support of this possibility, Reilly and Doherty (1992) reported higher correlations between explicit and implicit weights in the representative conditions of their experiments (in which existing cue intercorrelations were maintained) than in their orthogonal conditions (in which they were reduced/eliminated; see Dhami et al. [2004] for further discussion of the important impact of representative designs and Beckstead [2007] for an illuminating treatment of the statistical methods for assessing policy recognition tests). 


\subsection{Summary and conclusions}

The multiple-cue judgment literature presents a rich source of information about the potential role of unconscious influences. Although the received wisdom in studies of both novice and expert judges suggests poor insight into the factors underlying judgment, a close analysis of the data reveals a somewhat more optimistic picture. Our critique also highlights the importance of distinguishing genuine self-insight (or lack thereof) from artifacts that are inherent in the methods used to assess judgment. One possible solution to this problem is to adopt a verbal policy-capturing method in which structured interviews are used to elicit explicit policies. Ikomi and Guion (2000) used such a technique with flight instructors and found that such "declared" policies were more accurate in predicting judgments than implicit weights for 12 of their 19 participants. An alternative approach is to reconsider the model underlying judgment. Policy-capturing studies are wedded to the idea that judgments involve the weighting and adding of individual cues (i.e., a linear additive model), but people might be using similarity to previously encountered instances (Brooks et al. 1991), or applying sequential heuristics (Gigerenzer 2007) in making their judgments. These judgments might well be consciously mediated but would appear unconscious if participants were asked to explain what they were doing in terms of attribute weights, yielding inadvertent failure to meet the relevance criterion.

More research using various ways of assessing explicit knowledge is required before strong conclusions can be drawn, but at the very least we can say that many studies have revealed reliable access by participants into the thoughts underlying their judgments. 


\section{Deliberation without attention: does "not thinking" release the}

\section{powers of the unconscious?}

Dijksterhuis et al. (2006) made the bold claim that when faced with complex decisions (what car to buy, where to live), we are better advised to stop thinking and let our unconscious decide. Dijksterhuis et al. argued that explicit consideration of options and attributes overwhelms our capacity-limited conscious thought. In contrast, the unconscious is capacity-unlimited and can therefore weight information appropriately and decide optimally (Dijksterhuis \& Nordgren 2006). In terms of our framework, as with the studies reviewed in Section 2, unconscious processes are purported to exert influence at Point D in Fig. 1 - the weighting and integration of information to determine cue utilizations. Such advice flies in the face of standard prescriptions for decision making (e.g., Edwards \& Fasolo 2001; Newell et al. 2007) and also runs counter to research that has strongly challenged the related notion of “incubation" in creative thinking (Weisberg 2006), and so the evidence on which such claims are based deserves intense scrutiny.

In the standard experimental paradigm, participants are presented with information about three or four objects (e.g., cars) described by 10 or more attributes (e.g., mileage) and are asked to choose the best object. In most experiments best is determined normatively by the experimenter assigning different numbers of positive and negative attributes to each option. Attribute information is presented sequentially and typically in random order about the four options. Following presentation of the attributes, participants are assigned to one of three (or sometimes only two) conditions. In the unconscious thought condition, participants are prevented from making a decision for a few minutes by engaging in some distracting activity (e.g., 
solving anagrams). This distraction period is claimed to facilitate unconscious thought - “cognitive and/or affective task-relevant processes [which] take place outside of consciousness awareness" (Dijksterhuis 2004, p. 586). In the conscious thought condition participants are asked to think carefully about their choice for a few minutes, while in the immediate condition participants are simply asked to make their decision as soon as the presentation phase has finished.

The final choices made by participants in these three conditions reveal (sometimes) that distraction leads to better choices and/or better differentiation between good and bad options than either conscious thought or an immediate decision. For example, Dijksterhuis et al. (2006) reported that $60 \%$ of participants chose the best car after being distracted compared to only $25 \%$ following conscious deliberation. The literature on unconscious thought is now burgeoning; we focus on two key issues: the reliability of the effect and alternative explanations that do not necessitate the involvement of unconscious processes.

\subsection{Reliability of the unconscious-thought effect}

Demonstration of the benefit of unconscious thought on choice requires two criteria to be satisfied. First, choices following distraction need to be significantly better than those following deliberation, and, second, they need to be better than those following an immediate decision. In view of the amount that has been written about the merits of unconscious thought, it is surprising how rarely these criteria have been satisfied in one experiment. Both criteria are important. Demonstrating that distraction leads to better choices than deliberation could either mean that distraction is beneficial or that deliberation is detrimental. The latter conclusion is less surprising, especially if the conditions for deliberation are suboptimal (cf. Mamede et al. 2010; Newell et al. 2009; Payne et al. 2008; Shanks 2006; Wilson \& Schooler 1991). The second 
criterion is thus a crucial prerequisite for drawing any conclusions about the added benefit of unconscious thought.

In the first published work on unconscious thought, Dijksterhuis (2004) reported three experiments that compared attitude ratings and/or choices following distraction, deliberation, and immediate processing. None of these experiments satisfied the two criteria outlined above. Moreover there were troubling (and unexplained) patterns in the data. For example, in Experiments 1 and 3 significant differences between some conditions were only found for males who constituted the clear minority in the sample. Thus even in this foundational study the evidence for unconscious influences was rather flimsy. It appears that when it comes to the role of unconscious processes, once an (intuitive) idea has taken hold, a momentum appears to build that is belied by the strength of the existing data. But despite this rocky start, it is now clear that there are several demonstrations of the effect - both in terms of improvements relative to conscious thought and immediate thought (see Strick et al. 2011, for a meta-analysis), although experiments in which all three conditions are tested and significant differences are found between each are still the exception rather than the rule (e.g., Dijksterhuis et al. [2009] and Lerouge [2009] - but see González-Vallejo \& Phillips [2010] for a re-evaluation of the former).

These positive findings are, however, tempered by several studies that have compared all three thought conditions in a single experiment and failed to demonstrate any advantage of unconscious thought over conscious and/or immediate decisions (Acker 2008; Calvillo \& Penaloza 2009; Huizenga et al. 2012; Mamede et al. 2010; Newell et al. 2009; Payne et al. 2008; Rey et al. 2009; Thorsteinson \& Withrow 2009; Waroquier et al. 2010). The reliability of the effect is also questioned by an earlier meta-analysis of the unconscious-thought literature. Acker (2008) found that across 
17 data sets there was "little evidence" (p. 292) for an advantage of unconscious thought. He also found that the largest unconscious thought effects were in the studies with the smallest sample sizes. Note that this is exactly the pattern predicted if one adopts exploratory rather than confirmatory research practices (Simmons et al. 2011; Wagenmakers et al. 2011) and is also consistent with a publication bias operating (i.e., preferential publication of statistically significant effects - Renkewitz et al. 2011). ${ }^{5}$ In line with these conclusions, Newell and Rakow (2011) presented a Bayesian analysis of 16 unconscious-thought experiments from their laboratories (including both published and unpublished studies) and found overwhelming evidence in support of the null hypothesis of no difference between conscious and unconscious thought.

A charitable interpretation is that it is too early to draw strong conclusions about the robustness of the effect (cf. Hogarth 2010). Vagaries of procedures, experimental instructions, differences in population samples, and differences in stimulus materials are all likely to contribute noise and hamper interpretation. But what about those cases where an effect is found? Do such results necessitate the involvement of an intelligent unconscious?

\subsection{Explanations of the deliberation-without-attention effect}

Proponents of the unconscious-thought theory (UTT) argue that deliberation without attention works because of the increased capacity and superior information-weighting ability of unconscious relative to conscious thought (Dijksterhuis \& Nordgren 2006). However, substantiating these claims has proved somewhat problematic on both theoretical and empirical grounds (for a wide-ranging critique of the "capacity principle" of UTT, see, e.g., González-Vallejo et al. 2008,). With regard to superior weighting of information, the experimental evidence is equivocal at best. In the 
standard paradigm described above, participants' own subjective attribute weightings are ignored because the importance of attributes is predefined by the experimenter (e.g., Nordgren et al. 2011). Often this is done in an implausible manner. For example, in Dijksterhuis et al.'s (2006) study the number of cup holders in a car was deemed as important as the fuel economy (obviously cup holders are far more important): Both were given the same single-unit weight in the calculation of the best and worst cars. With these experimenter-defined weighting schemes, it is impossible to know whether the best choice is indeed the one favored by all participants.

Newell et al. (2009) examined this issue by asking participants, after choices had been made, for importance ratings for each attribute (e.g., How important are cup holders?). In so doing, Newell et al. were able to determine, retrospectively, the best option for each participant and then see how often participants chose the option predicted by their idiosyncratic weights. The results were clear: Regardless of the condition (conscious, unconscious, or immediate), the majority of participants chose the option predicted by their own idiosyncratic weights. In a similar vein, Dijksterhuis (2004) reported that conscious and unconscious thinkers did not differ significantly in terms of the correlations between their idiosyncratic attribute weightings and attitudes toward options.

This last finding was echoed in a recent study by Bos et al. (2011), who demonstrated that participants in both an immediate and an unconscious-thought condition were able to differentiate between cars that had a high number of "important" positive attributes (quality cars) from those that had several "unimportant" positive attributes (frequency cars) (a conscious thought condition was not included). While unconscious thinkers were significantly better at this differentiation (their difference scores were larger), there was no significant difference in the extent to which participants obeyed 
their own weighting schemes. Moreover, because a conscious thought comparison group was not run, we do not know if it was the operation of some active unconscious process that improved weighting or simply the additional time between presentation of the alternatives and the elicitation of the decision.

A study by Usher et al. (2011) sheds further light on the weighting issue. They asked participants to rate the set of attributes from which the objects were composed before the decision task. A unique set of objects was then created, via computer software, to ensure that one object was the best for each individual participant, one the worst, and two others in-between. The standard decision task was then conducted with conscious- and unconscious-thought groups (no immediate group was included). Almost $70 \%$ of the distracted participants chose the best option, while fewer than $30 \%$ of those asked to think carefully did so. This is a compelling result suggesting more optimal weighting in unconscious than conscious thought, but without the immediate group for comparison, the Usher et al. results (on their own) do not satisfy our earlier criteria: The added value of unconscious processing, relative to an immediate judgment, cannot be assessed.

Several authors have asked whether the deliberation-without-attention effect is due to disadvantages conferred on conscious thought via particular experimental procedures rather than any hypothesized advantages of unconscious thought. For example, Payne et al. (2008) examined whether conscious thinkers did poorly in the standard experimental task because they were forced to think about the problem for too long. Such persistence could, according to Payne et al., lead to a shift in attention toward less relevant information (cf., Rey et al. 2009; Wilson \& Schooler 1991). To test this idea, Payne et al. compared participants in the standard conscious- and unconsciousthought conditions with a "self-paced" conscious thought condition in which 
participants were told that they would have as much time as they liked to deliberate and decide. The results were clear-cut: Participants in the unconscious and self-paced conditions outperformed those in the conscious condition but did not differ from each other. Payne et al. interpreted this combination of findings as evidence for poor performance of inappropriately constrained conscious thought rather than for superiority of unconscious thought.

A second re-interpretation of the unconscious-thought effect focuses on the possibility that participants make their decisions before entering the deliberation or distraction periods. The notion is that because attribute information is presented serially (and often randomly) about each option, participants engage in on-line processing, updating their impression of each option as subsequent pieces of information are presented (e.g., Lassiter et al. 2009; Newell et al. 2009; cf. Hastie \& Park 1986). In the distraction condition, where post-information-acquisition processing is prevented (or discouraged), participants default to these on-line impressions when asked to make their final decision. In contrast, those given the opportunity to deliberate attempt to integrate the large amount of attribute information into a single "memory-based judgment" (Hastie \& Park 1986; Lassiter et al. 2009). The result is that the retrieved on-line judgments (or first impressions) are sometimes superior because conscious thinkers are hampered by fragmentary and poorly organized memory for the attributes (cf. Shanks 2006). Even authors who have challenged this interpretation (e.g., Strick et al. 2010) reported that $60 \%$ of their participants made decisions on-line. If this proportion is representative, then it provides a serious challenge to many previous studies that have argued that participants deliberate (either consciously or unconsciously) after information has been presented (for similar arguments, see also Newell \& Rakow 2011). 
Usher et al. (2011) attempted to counter these problems by using a novel procedure in which multiple periods of distraction/deliberation were interpolated between the presentations of attribute information. They argued that this interpolation reduced the likelihood of participants deciding before being exposed to the thought manipulation. Under these conditions a small advantage for unconscious thought was still found. This result is particularly striking because the conditions for deliberative thinking were more suitable - there was less chance that attribute information could have been forgotten, and there were fewer pieces of information to think about at each "thinking interval." Why filling these intervals with distraction (anagram solving) led to improvements in judgment remains a challenge to both the made-the-decision-before and the poor-conditions-for-deliberation alternative interpretations. However, even Usher et al. themselves did not take this result as unequivocal evidence for active unconscious processes (p. 10).

\subsection{Summary and conclusions}

The notion that "sleeping on it," in the sense of allowing a passage of time to elapse during which one is distracted, improves our decisions is enduring, appealing, and in line with anecdotal experience. Dijksterhuis and colleagues have struck a chord in the research community (and the public imagination) with an experimental paradigm that appears, to some extent, to provide empirical evidence for the soundness of the deliberation-without-attention recommendation. What is very clear, however, from our review is that the robustness and explanation of the deliberation-without-attention effect is far from settled (cf. Hogarth 2010). Given this state of affairs, suggestions to rely on the unconscious in applied domains such as legal reasoning (Ham et al. 2009) seem extremely premature. 
One noteworthy feature of the vast majority of unconscious-thought research on decision making is that it has been done with students making inconsequential, hypothetical choices about situations that they may not have much experience with for example, buying cars. Indeed, one of the few studies that examined the influence of distraction and deliberation in experts drew rather sobering conclusions for proponents of UTT. Mamede et al. (2010) showed that expert doctors given a structured diagnosis-elicitation-tool during the deliberation period produced more accurate diagnoses in complex cases than when they were distracted or made an immediate diagnosis. In fact, conscious deliberation gave rise to a $50 \%$ gain in diagnostic accuracy over an immediate diagnosis. This result illustrates that experts given appropriate conditions for deliberation can access relevant knowledge and improve their reasoning. Interestingly, in the same study novice doctors made poorer diagnoses in complex cases following deliberation compared to an immediate judgment (the accuracy of deliberative and distracted diagnoses did not differ) suggesting that the period of structured deliberation is only useful if particular key facts are already part of one's knowledge base (Mamede et al. 2010).

In summary, although the deliberation-without-attention effect has spurred welcome debate, ultimately, even if the effect can be reliably obtained, its existence falls well short of providing unequivocal evidence for the involvement of active unconscious processes in the construction of cue utilizations (Fig. 1, Point D).

\section{Awareness in decisions under uncertainty}

In decisions under uncertainty, the payoffs from the choice alternatives are unknown. Repeated sampling can allow these payoffs to be learned. Decision strategies then translate the learned payoffs into sequences of choices. 


\subsection{The Iowa Gambling Task}

Consider the choice between decks of cards where each card turned from each deck yields some reward or penalty, but nothing is known at the outset about the distribution of these outcomes. Someone playing this game has the opportunity to learn that the long-run payoffs of the decks differ and hence can adapt their sampling of the decks to reflect the payoffs. This essential structure describes the Iowa Gambling Task (IGT), devised by Bechara et al. (1994). In the years since it was first described and studied, a vast literature has grown up around this simple choice task (see Dunn et al. 2006).

The conventional structure of the task employs four card decks and 100 card selections. Two of the decks yield positive payoffs of $\$ 100$ for each card, and the remaining two decks yield payoffs of $\$ 50$. However, some of the cards yield simultaneous losses. These are programmed to be more substantial on the decks that yield $\$ 100$ payoffs such that in the long run these decks are disadvantageous and yield average net losses (equal to $-\$ 25$ ), while the decks with $\$ 50$ payoffs are advantageous and yield positive average net payoffs (equal to $+\$ 25$ ). Within each pair of decks, one has larger but less frequent punishments, but the average payoff is equal. Thus in the long run the best strategy is to select cards from one or both of the advantageous decks and avoid the disadvantageous ones.

In addition to assessing choice behavior in this task, Bechara et al. (1997) probed participants' awareness of the task structure. After the first 20 trials and then after every additional 10 trials, participants were asked to describe what they knew and felt about the task. The majority of participants eventually reached a "conceptual" period in which they were able to describe with confidence which were the good and bad decks, and in this period they unsurprisingly selected from the good decks on the 
majority of trials. Prior to the conceptual period was a "hunch" period, described by Bechara et al. (1997) as involving a reported liking for the good over the bad decks, but with low confidence and reports of guessing. In the phase before this (the "prehunch" phase) participants "professed no notion of what was happening in the game" (Bechara et al. 1997, p. 1294). Crucially, then, the question is whether awareness correlated with card selections or whether, in contrast, participants selected from the good decks in the prehunch phase before being aware of the differences between the decks in terms of their average payoff. It is this latter outcome that Bechara et al. (1997) claimed to observe in their data, concluding that "normals began to choose advantageously before they realized which strategy worked best" and that "in normal individuals, nonconscious biases guide behavior before conscious knowledge does" (p. 1293). Elsewhere, it has been claimed that "this biasing effect occurs even before the subject becomes aware of the goodness or badness of the choice s/he is about to make" (Bechara et al. 2000, p. 301).

Studies employing the IGT have a very natural interpretation within the lens model framework of Fig. 1. The decks can be conceived of as the cues, and their relationships to reward and punishment (the criterion) are captured by their ecological validities. The participant's goal is to judge the likely payoff for choosing each deck and to make a decision accordingly. If participants indeed learn to make advantageous deck selections, then their utilizations are appropriately tuned to the validities, yielding high achievement. Inability to report which are the good or bad decks is unawareness located at Point B in Fig. 1.

In view of the enormous amount written about the IGT and this pioneering study, it is remarkable to note that the key behavioral observation with regard to normal participants - more selections from good than bad decks in the prehunch period - was 
not in fact statistically significant in the Bechara et al. (1997) study. Preference for cards from the good decks was significant in the hunch and conceptual periods, but by that stage, of course, the participants possessed some conscious knowledge that could be guiding their choices. And the failure of this preference for the good decks in the prehunch period to reach significance is unlikely to be due simply to low power, because in two direct replications, with the same assessment of awareness, Maia and McClelland (2004) and Wagar and Dixon (2006) did not even observe a numerical preference for the good decks in the prehunch period.

In addition to their replication of the original study, Maia and McClelland (2004) tested another group of participants but employed a much more careful assessment of their awareness of the nature of the task at regular intervals. This careful assessment satisfied the criteria listed in Table 1. Rather than simply recording responses to openended questions regarding what they thought and felt about the task, Maia and McClelland required their participants to rate each deck on a numerical scale, to explain their numerical ratings, to report in detail what they thought the average net winnings or losses would be if 10 cards were selected from each deck, and to state which deck they would choose if they could only select from one deck for the remainder of the game. Answers to these questions provided a range of assessments of awareness against which actual card selections could be compared. In addition, Maia and McClelland ensured that the classification of decks as good or bad was based on the actual payoffs experienced by the individual participant to that point. Bechara et al. (1997) fixed the sequence of payoffs from each deck in the same way for each participant and scheduled very few penalties on the bad decks across the early trials. Thus a participant selecting early on from the bad decks might actually be making good choices, because the penalties that ultimately make such decks bad have not yet 
been experienced. Plainly, it is crucial to classify selections as good or bad in relation to what the participant has actually experienced, not in relation to the long-term but unknown average.

When card selections were compared to reported awareness under Maia and McClelland's (2004) improved method, it was apparent that awareness if anything was more finely tuned to the payoffs than the overt selections were. Far from observing selections from the good decks in participants who could not report which were the good decks, Maia and McClelland found that conscious reports about the decks were more reliable than overt behavior. This might indicate that participants were still exploring the task and acquiring further information about the decks, but it clearly provides no support for the claim that nonconscious biases occur before individuals have relevant conscious knowledge. Maia and McClelland's results were replicated by Wagar and Dixon (2006), and similar outcomes were obtained by Evans et al. (2005), Bowman et al. (2005), and Cella et al. (2007), who in three separate experiments found that preferential awareness ratings for the good over the bad decks emerged before the point at which preferential card selections favored the good decks. By the time behavioral choice revealed a preference for the good decks, awareness was sharply discriminating.

Maia and McClelland's (2004) study provides a particularly striking illustration of the dangers of employing an unreliable or insensitive test of awareness. In the Bechara et al. (1997) study, normal participants were reported to progress from the prehunch (no relevant awareness for discriminating the good and bad decks) to the hunch (some awareness that two of the decks were better than the others) phases at trial 50 on average, with no participant making this transition prior to trial 30 . In their replication using the Bechara et al. (1997) awareness questions, but with a more careful 
algorithm for making the awareness classification, Maia and McClelland located the average transition at about the same point. Yet in their second group of participants, in whom awareness was measured via numerical judgments, participants were clearly aware of the difference between the good and bad decks by the first assessment at trial 20 , and the onset of awareness has been located at a similar point in other studies (Evans et al. 2005; Wagar \& Dixon 2006). At this point, for example, $80 \%$ of Maia and McClelland's participants gave a good deck their highest numerical rating, and $85 \%$ of participants indicated one of the good decks when asked which deck they would choose if they could only select from one deck for the rest of the game. Thus on the Maia and McClelland assessment method, most participants had discriminative awareness by trial 20 (and possibly before then), whereas on the Bechara et al. (1997) method, none had such awareness prior to trial 30. The open-ended questions Bechara et al. (1997) used ("tell me all you know about what is going on in this game" and "tell me how you feel about this game"), together with their classification procedure for participants' responses to these questions, clearly did not comprise a sufficiently reliable and/or sensitive instrument for measuring awareness.

As noted earlier in this article, there has been much discussion about how best to measure awareness. Although they have attracted considerable controversy, alternatives to verbal report have been explored. Here we describe data from one study of decision making in the IGT that attempted to assess awareness without recourse to reports. Persaud et al. (2007) required their participants not only to make a deck selection on each trial, but also to wager on the payoff for that trial. The wager could either be a high (£20) or a low (£10) amount. The reward from the advantageous decks was equal to the amount wagered, while that from the disadvantageous decks was twice the amount wagered, with occasional penalties 
being larger on the disadvantageous decks. The point of the task is that wagering is assumed to provide a probe of the participant's awareness. If the participant has some awareness that his or her decision is a good one, then he or she should be willing to bet higher on that choice in order to obtain a higher payoff. Thus Persaud et al. speculated that choices from the good decks should tend to be accompanied by high wagers and choices from the bad decks by low wagers, if the participant has some awareness of the difference between the decks.

In a group of participants tested under these circumstances, the good decks began to be reliably selected by around trial 40 , but wagering did not begin to show a bias until trial 70. On the basis of this outcome, Persaud et al. (2007) argued that the initial preference for the good decks must be based on unconscious information.

There are, however, some substantial difficulties with this set of conclusions. First, to locate the onset of awareness at around trial 70 in the IGT is to run radically counter to the data obtained in other IGT studies when the first set of test questions is administered at trial 20. Several studies (as noted above) have found that the vast majority of participants give higher numerical estimates for the good compared to the bad decks the first time they are questioned (Persaud et al. (2007) did not report their own results from these awareness questions). Since the onset of a choice preference for the good decks is similar in the Persaud et al. study to that found elsewhere (around trial 40), it seems implausible to argue that the wagering component made the task harder overall and therefore delayed the onset of learning and awareness. Instead, it seems reasonable to speculate that wagering was measuring something other than awareness, or that it was measuring awareness insensitively or unreliably. This latter possibility is consistent with a second problem facing the wagering method of assessing awareness: Participants may have an aversion to risk or loss and hence may 
choose to make low wagers even when they have some degree of awareness.

Evidence that this is not just a theoretical speculation but also an empirical reality has been reported by Dienes and Seth (2010); and Konstantinidis and Shanks (2012) have found that when loss aversion is avoided, wagering very closely matches deck selections.

\subsection{Covert emotions in decisions under uncertainty}

The review in this section thus far has considered Bechara et al.'s (1997) behavioral evidence concerning unconscious biases in decision making. However, that research is influential for a further reason: Physiological markers of emotion were measured at the same time as card selections. Specifically, Bechara et al. $(1996 ; 1997)$ measured their participants' skin conductance responses (SCRs) prior to each choice. In normal participants, these responses, commonly assumed to measure bodily states of arousal and emotion, were found to be substantial after both rewards and punishments. Most importantly, though, they began to emerge during the course of the task in anticipation of card choices, in particular becoming larger before selections from bad than from good decks. Bechara et al. $(1996 ; 1997)$ took these SCRs to be "somatic markers," or covert emotional reactions capable of influencing behavior unconsciously, suggesting that "a negative somatic state as hallmarked by an anticipatory SCR, would nonconsciously "advise" the avoidance of the disadvantageous decks, while helping bring on line, cognitively the reasons for making the avoidance explicit" (Bechara et al. 1996, p. 224).

Of course, the evidence described above that participants' awareness in the IGT is quite extensive raises considerable doubt over the inference that these somatic markers are in any sense covert. On the contrary, they may be the effect rather than the cause of conscious thought, and indeed there is evidence in favor of this 
viewpoint. Gutbrod et al. (2006) measured SCRs as well as card choices and found that anticipatory SCRs did not begin to discriminate between good and bad decks until about trial 80 , yet card selections favored the good decks as early as trial 40 . In fact, this sequence is evident in Bechara et al.'s (1997) data too: Whereas significantly more cards were selected from good than from bad decks in the hunch period, anticipatory SCRs measured during that period were not significantly different for good versus bad decks. As Gutbrod et al. noted, this early development of a behavioral preference for the good decks cannot have been driven by the somatic markers measured in anticipatory SCRs. It could, on the other hand, have been driven by differential awareness which, as discussed above, emerges very early in the task. This temporal sequence - awareness $\rightarrow$ differential choice $\rightarrow$ differential SCRs seems to fit the data across these experiments well, with awareness being evident by around trial 20 , advantageous card selections by trial 40 , and differential anticipatory SCRs by around trial 80 .

The only recent study to provide support for the possibility that anticipatory SCRs precede the development of card selections is that of Wagar and Dixon (2006). These authors obtained the typical finding of advantageous card selections emerging at around trial 40, but in their data differential SCRs were evident by around trial 30. Although these results suggest that more work is needed before we fully understand the relative timing of and causal relationship between anticipatory SCRs and card selections, even Wagar and Dixon themselves did not take any of their results as evidence of unconscious influences on decision making. Their participants showed awareness at least as early as they showed a preference for the good decks.

Moreover, there is a major concern surrounding the interpretation of somatic markers. On Bechara et al.'s (1997) interpretation, they provide anticipatory information about 
the value of a particular choice option, especially for negative outcomes. Specifically, they are assumed to encode information about the negative emotions that were previously triggered by a stimulus or choice outcome, and then covertly guide subsequent decisions. On this account, whatever the individual's report may state, his or her decision is actually driven at least in part by an emotional marker of the valence of the choice outcome, a marker that is related to previous (especially negative) experiences independently of subjective belief. In contrast to this account, recent findings suggest that SCRs code the uncertainty associated with the participant's decision, not the outcome (Davis et al. 2009; Tomb et al. 2002). For example, Tomb et al. showed that when the IGT was modified so that it was the good rather than the bad decks that were associated with large payoffs and losses, SCRs tended to precede selections from the good decks. This strongly challenges the claim of the somatic marker hypothesis that such markers provide biasing signals for choice, because SCRs precede those choices (of bad decks) that are eventually eliminated in the standard IGT and precede those (of good decks) that eventually dominate in Tomb et al.'s modified version. Although it is possible that there are psychologically distinct somatic markers of positive and negative outcomes, it is plain that they cannot be distinguished by conventional SCR measurement.

\subsection{Summary and conclusions}

Of all the experimental methods used in recent years to study the role of awareness in decision making, the IGT and its variants have probably been studied more intensively than any others. The task lends itself quite naturally to a variety of awareness assessments and a range of behavioral indices, such as card choices and SCRs. While questions remain about important issues such as the suitability of using wagering as a means of gauging awareness, the evidence (particularly from Maia \& 
McClelland's [2004] major study) is clear in showing that participants acquire detailed conscious knowledge about the payoff structure at an early point during the task. This awareness emerges at least as early as behavioral differentiation itself, and there is little convincing evidence that decision making in the IGT is dissociable from awareness.

\section{Primes and primes-to-behavior}

In the present section we provide a highly abbreviated assessment of research using a range of priming techniques to influence behavior. In some research fields it has become widely accepted that priming can influence behavior unconsciously.

\subsection{Subliminal perception}

Subliminal perception is the controversial phenomenon whereby invisible stimuli may influence some aspect of behavior (see Fig. 1, Point C). It is intriguing that in the wake of a comprehensive methodological debate about 25 years ago (see Holender 1986), subliminal processing was afforded a rather modest role in most theoretical debates about the causation of behavior. Yet in recent years there has been a wealth of claims, based on subliminal perception experiments, concerning the importance of the unconscious in behavior including some striking reports of subliminal priming on decision making (e.g., Winkielman et al. 2005). Here we do not attempt to review this extensive literature. We do, however, briefly comment on the pervasive methodological problems that plague interpretation of results in this field (Dixon 1971; Holender 1986; Miller 2000; Pratte \& Rouder 2009), and we illustrate these problems with reference to a prominent and typical recent claim about subliminal influences on decision making. 
In a striking illustration, Hassin et al. (2007) primed their participants with a brief (16ms) masked presentation of either the Israeli flag or a scrambled version of the flag, prior to each of several questions about political attitudes (e.g., "Do you support the formation of a Palestinian state?") and voting intentions. Not only did the subliminal primes influence responses to these questions, but they also affected subsequent voting decisions in the Israeli general elections. Key evidence that the primes were invisible came from a test in which participants were shown the masked images and asked directly to indicate for each whether it was a flag or scrambled flag, which revealed chance-level performance.

There are substantial problems with this kind of inference. For instance, the form of awareness check employed by Hassin et al. (2007) is susceptible to bias if the participant's confidence about seeing the flag is low. On some occasions on which they actually see the flag, they may nonetheless respond "scrambled flag" because their judgment is uncertain and they adopt a conservative decision criterion.

Worse still, Pratte and Rouder (2009) have shown that typical tests used to measure awareness in subliminal perception experiments (such as that used by Hassin et al. 2007) may significantly underestimate conscious perception as a result of task difficulty. Because tests assessing perception of near-threshold stimuli are very difficult, participants may lose motivation. In their experiments, Pratte and Rouder maintained participants' motivation by intermixing above-threshold and nearthreshold stimuli and found that identification of the near-threshold stimuli increased reliably. Thus brief stimulus presentations that would have been regarded as subliminal in a conventional awareness test were found to be supraliminal in a modified test designed to be more closely equated to the main priming test in terms of difficulty. Until subliminal priming experiments are able to rule out such artifacts, 
their conclusions will remain in doubt. Recent methodological advances (e.g., Rouder et al. 2007) offer the promise of more clear-cut tests of subliminal perception in the future.

\subsection{Primes-to-behavior}

Other striking studies, largely emerging from social cognition, describe apparent influence of primes on behavior where the prime, but not its influence, is consciously perceived (Fig. 1, Point D). A number of instances have been reported in recent years, such as that individuals can be induced to act socially or unsocially, walk faster or slower, behave more or less intelligently, or perceive accurately or inaccurately as a result of subtle priming influences of which they are unaware. In Bargh et al.'s (1996) famous experiment, for example, participants read sentences containing words related to the concept old age and, as a consequence, a few minutes later walked more slowly down a corridor. Although few of these studies relate specifically to decision making, they are provocative illustrations of possible unconscious influences on behavior. ${ }^{6}$ Significant question marks exist concerning behavioral priming studies, particularly in regard to their assessment of awareness. The methods used for assessing awareness have generally been weak and fail the criteria described in Table 1. Bargh et al. (1996), for example, reported an experiment specifically designed to evaluate whether their participants were aware of the potential influence of the prime. Participants were randomly administered either the version of the task containing words relevant to the elderly stereotype or the neutral version containing no stereotype-relevant words. Immediately after completion of the task, participants were asked to complete a version of the contingency awareness funnel debriefing... [which] contained items concerning the purpose of the study, whether the participant had suspected that the purpose of the 
experiment was different from what the experimenter had explained, whether the words had any relation to each other, what possible ways the words could have influenced their behavior, whether the participants could predict the direction of an influence if the experimenter had intended one, what the words in the scrambled-sentence task could have related to (if anything), and if the participant had suspected or had noticed any relation between the scrambledsentence task and the concept of age. (p. 237)

Bargh et al. (1996) reported that only 1 of 19 participants showed any awareness of a relationship between the stimulus words and the elderly stereotype.

This experiment leaves a number of questions unresolved. For example, was there any difference between the two groups in their responses to any of the questions? No actual data were reported at all, let alone broken down by group. Why were questions about whether the purpose of the experiment might have been different from what the experimenter had explained, and about whether the words had any relation to one another, included in the awareness test? These issues are irrelevant to the critical issue, namely, whether the participant was conscious of the activation of the age concept. The only relevant question is the final one, whether the participant had noticed any relation between the scrambled sentences and the concept of age. All the other questions are irrelevant, and their inclusion simply adds noise to the overall score. Put differently, the groups may have differed on their answers to this question, but that difference might well have been submerged in the random variance added by the other questions. Worse still, Doyen et al. (2012) used the same walking speed task but with more careful awareness debriefing: Participants were required to choose among four pictures representing categories that could have been used as primes (athletic person, Arabic person, handicapped person, elderly). Doyen et al. found that 
primed participants had significantly greater awareness of the prime on this test than unprimed participants.

Unfortunately, weak methods are still being employed. In Ackerman et al.'s (2010) recent report that various social judgments can be nonconsciously influenced by haptic sensations, the only supporting evidence regarding awareness was that "Only one participant (in Experiment 5) reported awareness of the hypotheses, and so this person was removed from the analyses" (Supplementary Materials). How participants were probed about the influence of the primes on their behavior is not described, and whether or not they would have reported awareness if the criteria described in Table 1 had been satisfied (e.g., using sensitive methods such as rating scales) is unknown. Another major problem is that the replicability of many of these priming effects has yet to be established. Dijksterhuis et al. (1998; Study 2), Doyen et al. (2012), and Pashler et al. (2011) all failed to replicate Bargh et al.'s (1996) finding that priming the stereotype of elderly people can affect walking speed. In another priming situation, Bhalla and Proffitt (1999) reported that participants judged a hill as steeper when they were wearing a heavy backpack, but results from Durgin et al. (2009) found evidence that this priming effect is an artifact of compliance by participants to the perceived experimental hypothesis. In yet another example, Zhong and Liljenquist (2006) reported that asking participants to recall an unethical act from their past increased the accessibility of cleansing-related words and the likelihood of taking antiseptic wipes, yet the only published attempt to replicate these findings yielded four failures (Gámez et al. 2011). Until clear replications of these priming effects are reported, using more sophisticated assessments of awareness, it is premature to conclude that these studies provide robust evidence of unconscious influences on behavior. 


\subsection{Summary and conclusions}

Few topics in psychology excite as much attention in the media as research on priming effects with subtle but unnoticed or outright subliminal stimuli. Yet research in this field yields remarkably few effects that convincingly demonstrate unconscious influences. The claim that briefly presented primes fall outside consciousness is difficult to establish without extremely rigorous methods, but such methods are employed insufficiently often. The primes-to-behavior literature has also largely employed weak methods to assess awareness, there are question marks over the replicability of some of its most prominent findings, and selective publication bias and file drawer effects (Renkewitz et al. 2011) may be clouding the overall picture.

\section{Discussion}

We have articulated some of the conditions necessary to establish influences of unconscious mental states on decision making and have reviewed a considerable body of evidence in relation to multiple-cue judgment, deliberation without attention, decisions under uncertainty, and priming. From the perspective of our lens model framework, many of the claims for unconscious influences focus on Points B (unawareness of cue-criterion relations), C (unawareness of cues), and D (unawareness of cue utilization) (Fig. 1). However, when paradigm demonstrations are scrutinized, explanations that invoke unconscious processes appear unnecessary. Performance in tasks such as the IGT which is routinely cited as providing evidence for unawareness (at Point B) can be readily explained as mediated by conscious acquisition of deck knowledge (Maia \& McClelland 2004); subliminal priming experiments that might be considered optimal for demonstrating unawareness at Point C reveal awareness of primes (Pratte \& Rouder 2009); and studies of multiple-cue 
judgment suggest that people do possess knowledge of cue utilization (Point D; Reilly \& Doherty 1992). Moreover, manipulations designed to impact this utilization process unconsciously have limited and potentially artifactual effects (Newell et al. 2009; Payne et al. 2008). In summary, these research areas have so far failed to yield clear, replicable, and unequivocal demonstrations of unconscious influences. On the contrary, many careful experiments have documented consistently high levels of conscious access in people's causal reports on their behavior.

A surprising outcome of the review is that debates and disagreements about the meaning of the terms consciousness and awareness have (with a few exceptions) played a remarkably minor role in recent research. Whereas issues about how to define and measure awareness were once highly prominent and controversial (e.g., Campion et al. 1983; Reingold \& Merikle 1988), it now seems to be generally accepted that awareness should be operationally defined as reportable knowledge, and that such knowledge can only be evaluated by careful and thorough probing. Thus an encouraging conclusion is that the field seems to have generally taken heed of detailed recommendations (e.g., Ericsson \& Simon 1980) about suitable methodology in the assessment of awareness, including the requirements noted in Table 1 that awareness assessment must be reliable, relevant, immediate, and sensitive. We concur with Uhlmann et al. (2008) that claims of unconscious influences should ideally depend on more than simply confirming the null hypothesis (that evidence of awareness is not obtained). Null results are always ambiguous because the assessment may not have adequately met the criteria in Table 1 . Uhlmann et al. proposed a range of other findings, such as the absence of actor-observer differences, which may avoid these difficulties (though, as previously discussed, these findings have not been obtained under more careful assessments). 


\subsection{Brief comments on other research areas}

We noted in the Introduction that our focus is on those research areas that are most relevant to our overall question about the extent to which the mental processing that leads to the selection of one among several actions can be considered unconscious. To talk of brain systems making decisions is to use the notion of a decision very differently, and it is not clear what it would mean to ask whether the visual system's computation of size and distance, for example, is or is not conscious. Even with regard to the main areas reviewed in Sections 2-4, we have of necessity been selective in the studies we have reviewed, and we recognize that our critical viewpoint leaves us at risk of the objection that if we had considered areas X or Y, we would have found more compelling evidence. We maintain that the areas we have selected have been highly influential in bolstering claims for unconscious decision making, so it would be very surprising if the evidence is markedly weaker in these domains than elsewhere. Nevertheless, we briefly comment here on some other well-known areas. Our hope is that we can convey at least a flavor of why the common claims from these fields may be open to challenge.

\subsubsection{Automaticity}

When we look at the individual's use of low-level brain "decisions," do we see clear evidence of unconscious processing? This is far from obvious. Evidence that such decisions are cognitively impenetrable (in other words, immune from top-down attentional control and conscious knowledge) is very controversial. It is now known, for instance, that even something as low level and apparently automatic as motion processing in area V5 is dramatically attenuated in conditions of high cognitive load (Rees et al. 1997). Similarly, visuo-motor adaptation is influenced by conscious expectancies (Benson et al. 2011). 
Supposedly automatic processes like word reading and visual adaptation are frequently cited as examples of unconscious processing. The use of unconscious (meaning uncontrollable influences/processes) in this context is rather distinct, however, from what we have been concerned with in this article (unreportable influences or processes). The evidence suggests that very few influences or processes are truly uncontrollable. For example, it is well-known that Stroop interference which apparently reveals the automaticity of word reading - can be diluted by a range of manipulations of top-down control (Logan \& Zbrodoff 1979). Thus these examples have little bearing on the main question addressed in the present article.

\subsubsection{Neural precursors of motor responses}

Famously, Libet and colleagues (Libet 1985; Libet et al. 1983) reported experiments in which electroencephalographic activity was monitored while participants freely chose when to make a voluntary movement and reported the time point at which they felt the intention to move (Point E in Fig. 1). Participants observed a spot rotating on a clock and made their timing reports by observing the dot's location at the point of becoming conscious of their urge to move (these are called "will" or W judgments). Libet found that these judgments followed rather than preceded the first neural marker of movement intention, the readiness potential (RP), and indeed the time interval between these could be as much as a second. Libet and many subsequent commentators have taken these results as evidence that conscious intentions do not cause voluntary actions but are instead epiphenomenal effects of the true, unconscious causes of such actions, namely, neural events. Recent research has extended the method using recordings of activity in single neurons in medial frontal cortex (Fried et al. 2011), which show progressive recruitment over several hundred milliseconds prior to participants' reported experience of the urge to move. 
Several recent studies, adopting variants of Libet's method, serve if anything to support the intuitive Cartesian view that voluntary movements are caused by conscious decisions to act. Particularly noteworthy is a study by Trevena and Miller (2002) that compared lateralized readiness potentials (LRPs) to psychometrically determined $\mathrm{W}$ judgments. The LRP is a more appropriate indicator of hand-specific movement preparation than the RP, which, Trevena and Miller argued, is a marker of very general preparation for a future movement. As well as replicating Libet et al.'s (1983) finding that RPs preceded the mean time of W judgments, Trevena and Miller (2002) also found that the same was true for LRPs, although by a much smaller amount (approximately $180 \mathrm{~ms}$ ). Crucially, however, Trevena and Miller pointed out that comparing the onset of one measure (LRP) with the mean of another introduces bias. Instead, one onset needs to be compared with another. In their experiments, Trevena and Miller were able to determine the earliest point at which W judgments occurred (i.e., the onset of these judgments) and found evidence that they tended to precede, not follow, the LRPs.

An additional finding confirms that the RP is not - as Libet et al. (1983) supposed an appropriate measure of preparation for action execution. Miller et al. (2011) reported the striking finding that the RP "signature" of movement preparation was virtually eliminated in conditions where participants made voluntary movements but without a clock or any requirement to report $\mathrm{W}$ judgments. The implication of this is that the preparatory neural activity, which Libet took as evidence of unconscious movement preparation, has more to do with dividing attention and preparing to make a clock judgment. As Miller et al. noted, the clock procedure, which was designed to measure mental events, seems in fact to alter the neural activity to which these mental events are related. 


\subsubsection{Conscious will as an illusion}

The folk-psychological view that conscious thoughts cause our decisions and behavior faces a major obstacle in the substantial body of evidence suggesting that our conscious thoughts are often inferred after the fact. Rather than making conscious choices and immediately and passively experiencing those thoughts, an alternative possibility is that the thoughts are constructions created post hoc and that the true causal work is done by unconscious states of mind and brain. This is the essence of the will-as-illusion viewpoint, which emphasizes that experiencing an intention prior to an action is no guarantee that the intention caused the action. In one particular version of this approach, and in contrast to the intuitive view that our decisions and behaviors are caused by conscious intentions, it has been argued (particularly by Wegner 2004) that they are instead caused by unconscious processes that may simultaneously produce illusory experiences of conscious will. Specifically, it is proposed that unconscious states of mind/brain cause two things, both the voluntary action itself and a conscious thought about the action (intention). As a result of the constant conjunction of thought and action, an experience of will is created via illusory inference even though the thought itself is not the true cause of the action. Wegner drew an analogy with a ship's compass. Someone looking at the compass and relating it to the ship's course might form the impression that the compass is actually steering the ship, yet we know that the compass exerts no such control over the ship's movement. The compass reading is an effect, not a cause, of the ship's course, which is in fact caused by a whole raft of separate factors and processes such as the prevailing wind and the position of the ship's wheel and rudder.

Wegner's (2004) principal support for this theory comes from demonstrations that illusions of will can be created in which people either experience will when their 
conscious thoughts are objectively not the cause of their actions or fail to experience will when they objectively are. For example, Wegner et al. (2004) had participants watch themselves in a mirror with their arms out of view by their sides while a confederate stood behind them. The confederate's arms were extended forward to where the participant's arms would normally be, and these arms performed various actions such as giving an OK sign. When the participants heard instructions over headphones previewing each of these actions, they judged that they had greater control over the arms' movements. Wegner has concluded from such demonstrations that the experience of conscious will is an illusion in the same sense that the experience of physical causation is. In both cases, our minds draw inferences when the conditions are appropriate, namely, when constant conjunction is present. There have been numerous responses to Wegner's radical position on will and the conscious causation of behavior. Nahmias (2005) pointed out that the experiments do not induce anything remotely resembling full-scale experiences of agency. In Wegner et al.'s (2004) study, for example, participants rated their sense of vicarious control on 7-point scales (with $1=$ not at all and $7=$ very $m u c h$ ). Although participants reported a significantly enhanced feeling of control when the actions were previewed auditorily, their average ratings were never greater than 3 on this scale. Hence it can hardly be claimed that they reported experiencing a feeling of control over the confederate's actions. Moreover, it has been noted (McClure 2011) that we often experience will even when an intention precedes an action by a long interval (such as a vacation). The analogy with physical causation is curious because the conclusions drawn in the two cases seem very different. In the case of physical causation, even if it is accepted that our knowledge of causation is an inference based on constant conjunction, and that we can in consequence experience illusions of causation, most 
people do not conclude that physical causation itself is a fiction or that perception is generally illusory. Rather, we conclude that there are real causal connections in the world but that our knowledge of them is indirect and largely inferential (e.g., Harré \& Madden 1975). In contrast, on the basis of illusions of agency and will, Wegner's conclusion is that free will and the conscious causation of behavior are illusions. The illusions per se cannot prove this. They merely show that we lack direct access to linkages between thought and action.

\subsubsection{Blindsight}

Individuals with the condition known as blindsight report being experientially blind in a part of their visual field (scotoma) yet are able to make a variety of discriminations about stimuli presented in that part of the field. Blindsight results from damage to primary visual cortex, and because external space is represented retinotopically in primary visual cortex, there is a tight coupling between the location of the cortical damage and the location of the scotoma. Successful discrimination of location, movement, form, color, and so on, as well as overt actions such as pointing, have been reported in blindsight (Weiskrantz 1986), and it has been proposed that these behaviors must be based on unconscious representations, as blindsight patients deny visual consciousness regarding stimuli falling within their scotomata. In terms of the lens model, the deficit is located at Point $\mathrm{C}$ in Figure 1.

For almost as long as blindsight has been investigated, the possibility that the condition is simply degraded (near-threshold) normal vision has been hotly debated (see Campion et al. 1983; Weiskrantz 2009). It is possible that residual visual discriminations with near-threshold stimuli are accompanied by weak, but reliable, levels of visual awareness. In fact, individuals with blindsight often report forms of visual experience (Overgaard 2011). Cowey (2010) recently noted in regard of D.B., 
the patient whose performance led to the coining of the term blindsight, that "there is still no explanation ... for the revelation nearly 30 years after his operation, that he experiences visual after-images when a visual stimulus is turned off... How ironic if the discovery of blindsight proves to be based on a patient who does not possess it!" (p. 7).

Weiskrantz (2009) and others have argued against the degraded normal vision hypothesis by pointing out (among other things) that individuals with blindsight behave qualitatively differently from normal individuals. Signal detection theory can be used to show, for instance, that forced-choice guessing in blindsight about which interval contained a stimulus yields a higher discrimination measure than yes-no responses about whether a stimulus was presented, while in normal individuals measured discrimination is identical in the two conditions (Azzopardi \& Cowey 1997).

Overgaard and colleagues (Overgaard 2011; Overgaard et al. 2008; Ramsøy \& Overgaard 2004) have argued, however, that dichotomous measures that ask the individual to report (yes/no) whether a stimulus is visible systematically underestimate the extent of visual awareness (regardless of response bias). These authors have provided evidence that when participants (both normal and blindsight) are given the opportunity to report the clarity of their perceptual experience using a range of categories such as "no experience," "brief glimpse," "almost clear experience," and "clear experience," stronger correlations are observed between awareness and discrimination accuracy than is the case when awareness is measured with binary responses. As with other examples from neuropsychology, much of the evidence can be plausibly explained without recourse to unconscious influences. 


\subsection{The seduction of the unconscious}

Given these conclusions, it is surprising (to us) that there remains a pervasive view in the literature that unconscious processes serve an important explanatory function in theories of decision making. This prominence is most obvious in theories that contrast deliberative with intuitive decision making (see Evans 2008; Kahneman 2011; Keren \& Schul 2009). A recent version of this general view was proposed by Usher et al. (2011, p. 10, emphasis added), who advocate two interacting systems with the following qualities:

system-1 (intuition) is parallel, extracts gist (holistic), and results in affective states, which are open to phenomenological awareness (Block 2007) in their end result but not in their operation (or stages). While, in contrast, system-2 (deliberation) is sequential, rule-based (e.g., lexicographic), and has access to the stages of processing.

Our added emphasis highlights that Usher et al. (2011) operationalized the two systems, in large part, via access to phenomenological awareness. In essence, Usher et al.'s interpretation suggests that a decision maker relying purely on system-1 would have awareness only at Point E in Figure 1 (the "end result"), whereas one relying solely on system-2 would be aware at all points (A-E inclusive). Usher et al. emphasized, however, that many decisions will be a product of these two systems interacting. For example, in a multi-attribute judgment task, system-2 is responsible for sequentially inspecting attributes and alternatives (e.g., Does this car have cup holders?), while system-1 generates an "affective integration of the values" (p. 10). This approach is similar to that proposed by Glöckner and Betsch (2008) in their parallel-constraint satisfaction model of multi-attribute judgment and choice (see also Glöckner \& Witteman 2010). Our review suggests, however, that when participants 
are given adequate opportunities to report the knowledge underlying their behavior, there is little, if any, explanatory role played by a phenomenologically inaccessible affective integration process. While knowledge underlying behavior might not always be comprehensive, it is often sufficient to explain observed performance.

Why, then, do explanations that invoke unconscious mental states remain so popular? A superficial answer is that they make good stories that have clear appeal to a wide audience, especially when they involve expert decision making (e.g., Gladwell 2005; Lehrer 2009). A more considered answer acknowledges that as a field of study, the issue of unconscious influences is a challenging one to look at impartially because we all have such strong ex ante beliefs about the causation of our behavior and the circumstances in which we are unaware of its determinants. Consider the following illustration of the grip that our intuitions about the limits of conscious deliberation can hold. In a multiple-choice test, is it wise to change your answer on subsequent reflection? Suppose that you have been asked which city is more populous, Stockholm or Munich? You intuitively choose Stockholm, but then ponder your decision further. Perhaps you retrieve relevant information from memory such as that Munich has a famous soccer team whereas Stockholm does not. Should you change your answer in such circumstances where intuition and reason diverge? A majority of people believe that the answer is "no," and students often resist (and are advised by their teachers to resist) revising their initial responses, yet decades of research proves the contrary (e.g., Benjamin et al. 1984). In fact, revising initial answers tends to increase their accuracy (Munich is in fact more populous). In the face of such strong but mistaken intuitions about conscious deliberation, and the likely confirmation biases they induce, empirical evidence faces an uphill battle. 
Of course there are well-developed and influential frameworks that seek to offer principled accounts of the distinction between conscious and unconscious processing. The well-known global workspace theory of Baars (2002), for instance, roughly divides conscious from unconscious processes in terms of events that are or are not in the spotlight of selective attention. But such models start from the assumption that unconscious drivers of behavior exist, and this is the very assumption we believe is in need of critical scrutiny. We argue that many reports on unconscious biases have been influential in part because the audience has been strongly predisposed to believe them, even when alternative interpretations are available. Thus claims about the role of unconscious processes have not always been treated quite as critically by the academic community (including journal editors) as claims for which our intuitions are weaker. This can lead to the momentum effects we noted in our review in which (weak) evidence for an "intuitive" result is given undue weight and forms the basis for largely black-box explanations of behavioral phenomena.

This is not to deny that there are differences (phenomenological and otherwise) between a deliberation-based and an intuition-based decision. Nor is it to deny that sometimes deliberated decisions can be bad (e.g., Ariely \& Norton 2011; Wilson \& Schooler 1991), and fast decisions can be good (e.g., Goldstein \& Gigerenzer 2002). The first of these claims - that too much thinking about a decision can lead to poorer choices than only thinking a little -is not necessarily at odds with our framework. The deleterious effect of reasons analysis (conscious reporting of the bases for choice) would be captured by the inclusion of too many inappropriately weighted cues (Point D, Fig. 1).Such an effect does not necessitate unconscious influences but rather the ineffective use of conscious deliberative processes. If choices (or attitudes) change when people are asked to report underlying reasons, this does not necessarily imply 
that initial choices are the product of unconscious reasons (e.g., Uhlmann et al. 2008). A choice might change because additional information to that originally considered consciously might alter (sometimes detrimentally) a final choice. The simple point is that these decisions need not be based on unconscious knowledge - in the sense of lack of awareness of the knowledge and inferences underlying one's behavior.

With regard to the second claim - that fast decisions can be good - Simon's succinct statement that intuition is "nothing more and nothing less than recognition" (Simon 1992, p. 155) is a useful insight here ${ }^{7}$ (cf. Kahneman \& Klein 2009). Simon's analogy with recognition reminds us that intuition can be thought of as the product of overlearned associations between cues in the environment and our responses. In the same way that firefighters train for many years to recognize cue-outcome associations (e.g., Klein 1993), we all learn to make a multiplicity of mundane everyday decisions (what to wear, eat, watch on TV, etc.). Such decisions may appear subjectively fast and effortless because they are made on the basis of recognition: The situation provides a cue (e.g., portentous clouds), the cue gives us access to information stored in memory (rain is likely), and the information provides an answer (wear a raincoat) (Simon 1992). When such cues are not so readily apparent, or information in memory is either absent or more difficult to access, our decisions shift to become more deliberative (cf. Hammond 1996; Hogarth 2010). The two extremes are associated with different experiences. Whereas deliberative thought yields awareness of intermediate steps in an inferential chain, and of effortful combination of information, intuitive thought lacks awareness of intermediate cognitive steps (because there aren't any) and does not feel effortful (because the cues trigger the response). Intuition is, however, characterized by feelings of familiarity and fluency. Again, the simple point is that in neither situation do we need to posit "magical" unconscious processes 
producing answers from thin air (cf. Hogarth 2010; Kahneman \& Klein 2009). As we have seen, when one undertakes a critical examination of the empirical evidence for genuine unconscious influences on decision making, the evidence is remarkably weak.

\subsection{Recommendations for future research}

What recommendations can be drawn from past research that might fruitfully guide future explorations? One recommendation concerns the types of task that are studied. It is hard to foresee much progress if the focus is on highly reflective situations such as the IGT or experiments in the deliberation-without-attention framework. These experimental tasks explicitly instruct the participant to make a particular decision and either seek evidence that introspective reports about the decision process are incomplete (IGT) or else that promoting further conscious reflection hinders decision accuracy (deliberation-without-attention studies). Moreover, in these sorts of tasks, participants are fully aware of the independent variables (reward magnitudes in the IGT, positive and negative attributes in deliberation-without-attention studies). It seems unsurprising that when participants are focusing on a particular decision problem, their introspections about their own mental processes and about the influences of the independent variables on their behavior can be quite insightful. Turning to neuroscience and neuropsychology for clear answers also appears problematic given the controversies surrounding many purported demonstrations of unconscious influences (see Section 6.1).

More promising is to look at situations in which attention is diverted away from the experimenter's hypothesis, such as those that look for subtle priming influences on behavior. The prime-to-behavior literature (sect. 5.2) includes many examples in which participants are unlikely to be aware of the potential influence of a prime on 
their behavior. Although the interpretation and replicability of many of these findings is in dispute, the basic logic of the experiments seems sound for investigating unconscious influences. A notable example of a very different type is Richardson et al.'s (2009) demonstration that choices can be influenced by relating the choice to eye movements. Participants in their study considered questions such as "Is murder sometimes justifiable?" and their gaze was monitored as they looked at onscreen yes and no buttons. They were required to choose as soon as the buttons disappeared. Richardson et al. arranged for the buttons to disappear when the participant's gaze had rested on one of them for $500 \mathrm{~ms}$ and found that "yes" responses were about $10 \%$ more likely when gaze had been on the yes than the no button. This and many other such subtle priming effects offer considerable promise for future exploration of insight, awareness, and decision making.

\subsection{Conclusion}

In summary, evidence for the existence of robust unconscious influences on decision making and related behaviors is weak, and many of the key research findings either demonstrate directly that behavior is under conscious control or can be plausibly explained without recourse to unconscious influences. Few topics in the behavioral sciences are as fundamental as this or run across as many subdisciplines of experimental psychology. Future research must take seriously the experimental and theoretical challenges that our critical review has highlighted.

\section{ACKNOWLEDGMENTS}

The support of the Australian Research Council (DP 0877510; DP 110100797; FT110100151) to the first author is gratefully acknowledged. We thank Magda Osman, David Lagnado, Peter Lovibond, Adam Harris, and Jon Baron for insightful 
discussions and comments on an earlier draft of the manuscript. We also thank the University of New South Wales students who participated in the 2010 and 2011 Unconscious Influences on Decision Making seminar course.

\section{NOTES}

1. We use the terms decision making and judgment throughout the article. A decision can be conceptualized as guided by the judgment process, which in turn refers to the evaluation of evidence pertaining to different options (see Baron 2008).

2. Our illustrative use of the lens model departs somewhat from traditional Brunswikian perspectives (e.g., Dhami et al. 2004). For example, in our conceptualization the criterion (Point A) can exert a causal influence on judgment.

3. The terms proximal and distal here refer to temporal characteristics of the cues and should not be confused with the use of the same terms in the traditional lens model framework.

4. Because this point is so crucial we provide another illustration of our alternative approach to explaining cases where individuals appear unaware of an influence on their behavior. In striking research on racial stereotypes in criminal sentencing, Blair et al. (2004a) found that both black and white prison inmates with more Afrocentric features (e.g., darker skin, wide nose, full lips) received harsher sentences than those with fewer such features, and suggested that this form of stereotyping is outside people's awareness and control. But Blair et al. (2004a) provided no evidence that number of Afrocentric features was the proximal cause of behavior, and it is easy to imagine that some other feature was instead. For instance, suppose that number of Afrocentric features in faces is correlated, in the minds of judges, with some other attribute such as hostility or low intelligence. Use of this correlated attribute might be 
entirely conscious (though of course deeply unjust). Moreover, it would not be surprising on this alternative hypothesis that participants are unable to control the influence of Afrocentric features on their judgments (Blair et al. 2004b).

5. A more recent and much larger meta-analysis of the unconscious-thought literature by Strick et al. (2011) does not discuss the relationship between $N$ and effect size.

6. Some of these effects have been interpreted as arising from direct perceptionaction links, and if that indeed is their basis, then the involvement of decision making processes would be minimal. However, it has become clear that these effects are highly inferential and almost certainly do recruit aspects of central decision processes (see Loersch \& Payne 2011). For example, primes sometimes produce assimilative effects and sometimes contrast effects.

7. In a similar vein, Albert Einstein once noted that "intuition is nothing but the outcome of earlier intellectual experience" (In a letter to Dr. H. L. Gordon on March 5, 1949; Albert Einstein Archives 58-217, as cited in Isaacson 2007.)

References [Ben R. Newell and David R. Shanks] [aBRN]

Acker, F. (2008) New findings on unconscious versus conscious thought in decision making: Additional empirical data and meta-analysis. Judgment and Decision Making 3:292-303. [aBRN]

Ackerman, J. M., Nocera, C. C. \& Bargh, J. A. (2010) Incidental haptic sensations influence social judgments and decisions. Science 328:1712-15.[aBRN]

Adair, J. G. \& Spinner, B. (1981) Subjects' access to cognitive processes: Demand characteristics and verbal report. Journal for the Theory of Social Behaviour 11:31-52. [aBRN]

Ariely, D. \& Norton, M. I. (2011) From thinking too little to thinking too much: A continuum of decision making. Wiley Interdisciplinary Reviews: Cognitive Science 2:39-46. [aBRN]

Arkes, H. R. (1981) Impediments to accurate clinical judgment and possible ways to minimize their impact. Journal of Consulting and Clinical Psychology 49:323-30. [aBRN]

Azzopardi, P. \& Cowey, A. (1997) Is blindsight like normal, near-threshold vision? Proceedings of the National Academy of Sciences 94:14190-94. [aBRN] 
Baars, B. J. (2002) The conscious access hypothesis: Origins and recent evidence. Trends in Cognitive Sciences 6:47-52. [aBRN]

Balzer, W. K., Rohrbaugh, J. \& Murphy, K. R. (1983) Reliability of actual and predicted judgments across time. Organizational Behavior and Human Performance 32:109-23. [aBRN]

Bargh, J. A., Chen, M. \& Burrows, L. (1996) Automaticity of social behavior: Direct effects of trait construct and stereotype activation on action. Journal of Personality and Social Psychology 71:230-44. [aBRN]

Baron, J. (2008) Thinking \& deciding (4th Edition). Cambridge University Press. [aBRN]

Baumeister, R. F., Masicampo, E. J. \& Vohs, K. D. (2011) Do conscious thoughts cause behavior? Annual Review of Psychology 62:331-61. [aBRN]

Bechara, A., Damasio, H. \& Damasio, A. R. (2000) Emotion, decision making and the orbitofrontal cortex. Cerebral Cortex 10:295-307. [aBRN]

Bechara, A., Damasio, A. R., Damasio, H. \& Anderson, S. W. (1994) Insensitivity to future consequences following damage to human prefrontal cortex. Cognition 50:7-15. [aBRN]

Bechara, A., Damasio, H., Tranel, D. \& Damasio, A. R. (1997) Deciding advantageously before knowing the advantageous strategy. Science 275:129395. [aBRN]

Bechara, A., Tranel, D., Damasio, H. \& Damasio, A. R. (1996) Failure to respond autonomically to anticipated future outcomes following damage to prefrontal cortex. Cerebral Cortex 6:215-25. [aBRN]

Beckstead, J. W. (2007) A note on determining the number of cues used in judgment analysis studies: The issue of type II error. Judgment and Decision Making 2:317-25. [aBRN]

Benjamin, L. T., Cavell, T. A. \& Shallenberger, W. R. (1984) Staying with initial answers on objective tests: Is it a myth? Teaching of Psychology 11:133-41. [aBRN]

Benson, B. L., Anguera, J. A. \& Seidler, R. D. (2011) A spatial explicit strategy reduces error but interferes with sensorimotor adaptation. Journal of Neurophysiology 105:2843-51. [aBRN]

Bhalla, M. \& Proffitt, D. R. (1999) Visual-motor recalibration in geographical slant perception. Journal of Experimental Psychology: Human Perception and Performance 25:1076-96. [aBRN]

Blair, I. V., Judd, C. M. \& Chapleau, K. M. (2004a) The influence of Afrocentric facial features in criminal sentencing. Psychological Science 15:674-79. [aBRN]

Blair, I. V., Judd, C. M. \& Fallman, J. L. (2004b) The automaticity of race and Afrocentric facial features in social judgments. Journal of Personality and Social Psychology 87:763-78. [aBRN]

Bos, M. W., Dijksterhuis, A. \& van Baaren, R. (2011) The benefits of "sleeping on things": Unconscious thought leads to automatic weighting. Journal of Consumer Psychology 21:4-8.[aBRN]

Block, N. (2007). Consciousness, accessibility, and the mesh between psychology and neuroscience. Behav. Brain Sci. 30, 481-499. [aBRN]

Bowman, C. H., Evans, C. E. Y. \& Turnbull, O. H. (2005) Artificial time constraints on the Iowa Gambling Task: The effects on behavioural performance and subjective experience. Brain and Cognition 57:21-25. [aBRN] 
Brooks, L. R., Norman, G. R. \& Allen, S. W. (1991) The role of specific similarity in a medical diagnostic task. Journal of Experimental Psychology: General, 120:278-87. [aBRN]

Brooks, L. R. \& Vokey, J. R. (1991) Abstract analogies and abstracted grammars: Comments on Reber (1989) and Mathews et al. (1989) Journal of Experimental Psychology: General 120:316-23. [aBRN]

Brunswik, E. (1952) The conceptual framework of psychology. University of Chicago Press. [aBRN]

Calvillo, D. P. \& Penaloza, A. (2009) Are complex decisions better left to the unconscious? Further failed replications of the deliberation-without-attention effect. Judgment and Decision Making 4:509-17. [aBRN]

Campion, J., Latto, R. \& Smith, Y. M. (1983) Is blindsight an effect of scattered light, spared cortex, and near-threshold vision? Behavioral and Brain Sciences 6:423-86. [aBRN]

Cella, M., Dymond, S., Cooper, A. \& Turnbull, O. (2007) Effects of decision-phase time constraints on emotion-based learning in the Iowa Gambling Task. Brain and Cognition 64:164-69. [aBRN]

Cowey, A. (2010) The blindsight saga. Experimental Brain Research 200:3-24. [aBRN]

Crandall, B. \& Getchell-Reiter, K. (1993) Critical decision method: A technique for eliciting concrete assessment indicators from the "intuition" of NICU nurses. Advances in Nursing Sciences 16:42-51. [aBRN]

Davis, T., Love, B. C. \& Maddox, W. T. (2009) Anticipatory emotions in decision tasks: Covert markers of value or attentional processes? Cognition 112:195200. [aBRN]

Dawes, R. M., Faust, D. \& Meehl, P. E. (1989) Clinical versus actuarial judgment. Science 4899:1668-74. [aBRN]

Dawson, M. E. \& Reardon, P. (1973) Construct validity of recall and recognition postconditioning measures of awareness. Journal of Experimental Psychology 98:308-15. [aBRN]

Dayan, E. \& Bar-Hillel, M. (2011) Nudge to nobesity II: Menu positions influence food orders. Judgment and Decision Making 6:333-42. [aBRN]

Dhami, M. K., Hertwig, R. \& Hoffrage, U. (2004) The role of representative design in an ecological approach to cognition. Psychological Bulletin 130:959-88. [aBRN]

Dienes, Z. \& Seth, A. (2010) Gambling on the unconscious: A comparison of wagering and confidence ratings as measures of awareness in an artificial grammar task. Consciousness and Cognition 19:674-81. [aBRN]

Dijksterhuis, A. (2004) Think different: The merits of unconscious thought in preference development and decision making. Journal of Personality and Social Psychology 87:586-98. [aBRN]

Dijksterhuis, A., Bos, M. W., Nordgren, L. F. \& van Baaren, R. B. (2006) On making the right choice: The deliberation-without-attention effect. Science 311:10051007. [aBRN]

Dijksterhuis, A., Bos, M. W., van der Leij, A. \& van Baaren, R. (2009) Predicting soccer matches after unconscious and conscious thought as a function of expertise. Psychological Science 20:1381-87. [aBRN]

Dijksterhuis, A. \& Nordgren, L. F. (2006) A theory of unconscious thought. Perspectives on Psychological Science 1:95-109. [aBRN] 
Dijksterhuis, A., Spears, R., Postmes, T., Stapel, D. A., Koomen, W., van Knippenberg, A. \& Scheepers, D. (1998) Seeing one thing and doing another: Contrast effects in automatic behavior. Journal of Personality and Social Psychology 75:862-71. [aBRN]

Dixon, N. F. (1971) Subliminal perception: The nature of a controversy. McGrawHill. [aBRN]

Doyen, S., Klein, O., Pichon, C.-L. \& Cleeremans, A. (2012) Behavioral priming: It's all in the mind, but whose mind? PLoS One 7:e29081. [aBRN]

Dunn, B. D., Dalgleish, T. \& Lawrence, A. D. (2006) The somatic marker hypothesis: A critical evaluation. Neuroscience and Biobehavioral Reviews 30:239-71. [aBRN]

Durgin, F. H., Baird, J. A., Greenburg, M., Russell, R., Shaughnessy, K. \& Waymouth, S. (2009) Who is being deceived? The experimental demands of wearing a backpack. Psychonomic Bulletin \& Review 16:964-968. [aBRN]

Edwards, W. \& Fasolo, B. (2001) Decision technology. Annual Review of Psychology 52:581-606. [aBRN]

Ericsson, K. A. \& Simon, H. A. (1980) Verbal reports as data. Psychological Review $87: 215-51 .[\mathrm{aBRN}]$

Evans, J. St. B. T. (2008) Dual-processing accounts of reasoning, judgement and social cognition. Annual Review of Psychology 59:255-78. [aBRN]

Evans, J. St. B. T., Clibbens, J., Cattani, A., Harris, A. \& Dennis, I. (2003) Explicit and implicit processes in multicue judgment. Memory \& Cognition 31:608-18. [aBRN]

Evans, C. E. Y., Bowman, C. H. \& Turnbull, O. H. (2005) Subjective awareness on the Iowa Gambling Task: The key role of emotional experience in schizophrenia. Journal of Clinical and Experimental Neuropsychology 27:656-64. [aBRN]

Fried, I., Mukamel, R. \& Kreiman, G. (2011) Internally generated preactivation of single neurons in human medial frontal cortex predicts volition. Neuron 69:548-62. [aBRN]

Gámez, E., Díaz, J. M. \& Marrero, H. (2011) The uncertain universality of the Macbeth effect with a Spanish sample. Spanish Journal of Psychology 14:156-62. [aBRN]

Gavanski, I. \& Hoffman, C. (1987) Awareness of influences on one's own judgments: The roles of covariation detection and attention to the judgment process. Journal of Personality and Social Psychology 52:453-63. [aBRN]

Gigerenzer, G. (2007) Gut feelings: The intelligence of the unconscious. Viking Press. [aBRN]

Gladwell, M. (2005) Blink: The power of thinking without thinking. Penguin. [aBRN]

Glöckner, A. \& Betsch, T. (2008) Multiple-reason decision making based on automatic processing. Journal of experimental psychology: Learning, memory, and cognition 34:1055-75. [aBRN]

Glöckner, A. \& Witteman, C. (2010) Beyond dual-process models: A categorisation of processes underlying intuitive judgement and decision making. Thinking \& Reasoning 16:1-25. [aBRN]

Gold, J. I. \& Shadlen, M. N. (2007) The neural basis of decision making. Annual Review of Neuroscience 30:535-74. [aBRN]

Goldstein, D. G. \& Gigerenzer, G. (2002) Models of ecological rationality: The recognition heuristic. Psychological Review 109:75-90. [aBRN] 
González-Vallejo, C., Lassiter, G. D., Bellezza, F. S. \& Lindberg, M. J. (2008) “Save angels perhaps": A critical examination of unconscious thought theory and the deliberation-without-attention effect. Review of General Psychology 12:28296. [aBRN]

González-Vallejo, C. \& Phillips, N. (2010) Predicting soccer matches: A reassessment of the benefit of unconscious thinking. Judgment and Decision Making 5:200206. [aBRN]

Guerin, B. \& Innes, J. M. (1981) Awareness of cognitive processes: Replications and revisions. Journal of General Psychology 104:173-89. [aBRN]

Gutbrod, K., Kroužel, C., Hofer, H., Müri, R., Perrig, W. \& Ptak, R. (2006) Decisionmaking in amnesia: Do advantageous decisions require conscious knowledge of previous behavioural choices? Neuropsychologia 44:1315-24. [aBRN]

Ham, J., van den Bos, K. \& van Doorn, E. A. (2009) Lady justice thinks unconsciously: Unconscious thought can lead to more accurate justice judgments. Social Cognition 27:509-21. [aBRN]

Hammond, K. R. (1996) Human judgment and social policy: Irreducible uncertainty, inevitable error, unavailable injustice. Oxford University Press. [aBRN]

Hammond, K. R. \& Stewart, T. R., eds. (2001) The essential Brunswik: Beginnings, explications, applications. Oxford University Press. [aBRN]

Harré, R. \& Madden, E. H. (1975) Causal powers: A theory of natural necessity. Blackwell. [aBRN]

Harries, C., Evans, J. St. B. T. \& Dennis, I. (2000) Measuring doctors' self-insight into their treatment decisions. Applied Cognitive Psychology 14:455-77. [aBRN]

Hassin, R. R., Ferguson, M. J., Shidlovski, D. \& Gross, T. (2007) Subliminal exposure to national flags affects political thought and behavior. Proceedings of the National Academy of Sciences 104:19757-61. [aBRN]

Hastie, R. \& Park, B. (1986) The relationship between memory and judgment depends on whether the judgment task is memory-based or on-line. Psychological Review 93:258-68. [aBRN]

Hogarth, R. M. (2001) Educating intuition. University of Chicago Press. [aBRN]

Hogarth, R. M. (2010) Intuition: A challenge for psychological research on decision making. Psychological Inquiry 21:338-53. [aBRN]

Holender, D. (1986) Semantic activation without conscious identification in dichotic listening, parafoveal vision, and visual masking: A survey and appraisal. Behavioral and Brain Sciences 9, 1-66. [aBRN]

Huizenga, H., Wetzels, R., van Ravenzwaaij, D. \& Wagenmakers, E.-J. (2012) Four empirical tests of unconscious thought theory. Organizational Behavior and Human Decision Processes 117:332-40. [aBRN]

Ikomi, P. A. \& Guion, R. M. (2000) The prediction of judgment in realistic tasks: An investigation of self-insight. International Journal of Aviation Psychology 10:135-53. [aBRN]

Isaacson, W. (2007) Einstein: His life and universe. Simon \& Schuster.

Johnstone, T. \& Shanks, D. R. (2001) Abstractionist and processing accounts of implicit learning. Cognitive Psychology 42:61-112. [aBRN]

Kahneman, D. (2011) Thinking, fast and slow. Allen Lane. [aBRN]

Kahneman, D. \& Klein, G. (2009) Conditions for intuitive expertise: A failure to disagree. American Psychologist 64:515-26. [aBRN]

Karelaia, N. \& Hogarth, R. M. (2008) Determinants of linear judgment: A metaanalysis of lens model studies. Psychological Bulletin 134:404-26. [aBRN] 
Kelley, H. \& Friedman, D. (2002) Learning to forecast price. Economic Inquiry 40:556-73. [aBRN]

Keren, G. \& Schul, Y. (2009) Two is not always better than one: A critical evaluation of two-system theories. Perspectives on Psychological Science 4:533-50. [aBRN]

Klein, G. (1993) A recognition primed decision (RDP) model of rapid decision making. In: Decision making in action: Models and methods, ed. G. Klein, J. Oransu, R. Calderwood \& C. Zsambok, pp. 138-47. Ablex. [aBRN]

Konstantinidis, E \& Shanks, D.R. (2012). Don't bet on it! Wagering as a measure of awareness in decision making under uncertainty Unpubished manuscript. University College London. [aBRN]

Lagnado, D. A., Newell, B. R., Kahan, S. \& Shanks, D. R. (2006) Insight and strategy in multiple cue learning. Journal of Experimental Psychology: General 135:162-83. [aBRN]

Lassiter, D. G., Lindberg, M. J., González-Vallejo, C., Bellezza, F. S. \& Phillips, N. D. (2009) The deliberation-without-attention effect: Evidence for artifactual interpretation. Psychological Science 20:671-75. [aBRN]

Lehrer, J. (2009) The decisive moment: How the brain makes up its mind. Text. [aBRN]

Lerouge, D. (2009) Evaluating the benefits of distraction on product evaluations: The mind-set effect. Journal of Consumer Research 36:367-79. [aBRN]

Li, Y. \& Epley, N. (2009) When the best appears to be saved for last: Serial position effects on choice. Journal of Behavioral Decision Making 22:378-89. [aBRN]

Libet, B. (1985) Unconscious cerebral initiative and the role of conscious will in voluntary action. Behavioral and Brain Sciences 8:529-39. [aBRN]

Libet, B., Gleason, C. A., Wright, E. W. \& Pearl, D. K. (1983) Time of conscious intention to act in relation to onset of cerebral-activity (readiness potential): The unconscious initiation of a freely voluntary act. Brain 106:623-42. [aBRN]

Loersch, C. \& Payne, B. K. (2011) The situated inference model: An integrative account of the effects of primes on perception, behavior, and motivation. Perspectives on Psychological Science 6:234-52. [aBRN]

Logan, G. D. \& Zbrodoff, N. J. (1979) When it helps to be misled: Facilitative effects of increasing the frequency of conflicting stimuli in a Stroop-like task. Memory \& Cognition 7:166-74. [aBRN]

Lovibond, P. F. \& Shanks, D. R. (2002) The role of awareness in Pavlovian conditioning: Empirical evidence and theoretical implications. Journal of Experimental Psychology: Animal Behavior Processes 28:3-26. [aBRN]

Maia, T. V. \& McClelland, J. L. (2004) A reexamination of the evidence for the somatic marker hypothesis: What participants really know in the Iowa Gambling Task. Proceedings of the National Academy of Sciences 102:1607580. [aBRN]

Mamede, S., Schmidt, H. G., Rikers, R. M. J. P, Custers, E .J. F. M., Splinter, T. A. W. \& van Saase, J. L. C. M. (2010) Conscious thought beats deliberation without attention in diagnostic decision-making: At least when you are an expert. Psychological Research 74:586-92. [aBRN]

Mantonakis, A., Rodero, P., Lesschaeve, I. \& Hastie, R. (2009) Order in choice: Effects of serial position on preferences. Psychological Science 20:1309-12. [aBRN] 
Marcus, G. F., Vijayan, S., Bandi Rao, S. \& Vishton, P. M. (1999) Rule learning by seven-month-old infants. Science 283:77-80. [aBRN]

McClure, J. (2012) Attributions, causes, and actions: Is the consciousness of will a perceptual illusion? Theory \& Psychology 22: 402-19. [aBRN]

Meehl, P. E. (1954) Clinical vs. statistical prediction. University of Minnesota Press. [aBRN]

Miller, J. (2000) Measurement error in subliminal perception experiments: Simulation analyses of two regression methods. Journal of Experimental Psychology: Human Perception and Performance 26:1461-77. [aBRN]

Miller, J., Shepherdson, P. \& Trevena, J. (2011) Effects of clock monitoring on electroencephalographic activity: Is unconscious movement initiation an artifact of the clock? Psychological Science 22:103-109. [aBRN]

Nahmias, E. (2005) Agency, authorship, and illusion. Consciousness and Cognition 14:771-85. [aBRN]

Newell, B. R. \& Bright, J. E. H. (2002) Well past midnight: Calling time on implicit invariant learning? European Journal of Cognitive Psychology 14:185-205. [aBRN]

Newell, B. R., Lagnado, D. A. \& Shanks, D. R. (2007) Straight choices: The psychology of decision making. Psychology Press. [aBRN]

Newell, B. R. \& Rakow, T. (2011) Revising beliefs about the merits of unconscious thought: Evidence in favor of the null hypothesis. Social Cognition 29:71126. [aBRN]

Newell, B. R., Wong, K. Y., Cheung, J. C. \& Rakow, T. (2009) Think, blink or sleep on it? The impact of modes of thought on complex decision making. Quarterly Journal of Experimental Psychology 62:707-32. [aBRN]

Nisbett, R. E. \& Wilson, T. D. (1977) Telling more than we can know: Verbal reports on mental processes. Psychological Review 84:231-59. [aBRN]

Nordgren, L. F., Bos M. W. \& Dijksterhuis, A. (2011) The best of both worlds: Integrating conscious and unconscious thought best solves complex decisions. Journal of Experimental Social Psychology 47:509-11. [aBRN]

Overgaard, M. (2011) Visual experience and blindsight: A methodological review. Experimental Brain Research 209:473-79. [aBRN]

Overgaard, M., Fehl, K., Mouridsen, K., Bergholt, B. \& Cleeremans, A. (2008) Seeing without seeing? Degraded conscious vision in a blindsight patient. PLoS One 3:e3028. [aBRN]

Pashler, H., Harris, C. \& Coburn, N. (2011, September 15) Elderly-related words prime slow walking. Retrieved May 30, 2012, from http://www.PsychFileDrawer.org/replication.php?attempt=MTU\%3D. [aBRN]

Payne, J. W., Samper, A., Bettman, J. R. \& Luce, M. F. (2008) Boundary conditions on unconscious thought in complex decision making. Psychological Science 19:1118-23. [aBRN]

Persaud, N., McLeod, P. \& Cowey, A. (2007) Post-decision wagering objectively measures awareness. Nature Neuroscience 10:257-261. [aBRN]

Phelps, R. H. \& Shanteau, J. (1978) Livestock judges: How much information can an expert use? Organizational Behavior and Human Performance 21:209-219. [aBRN]

Pothos, E. M. (2007) Theories of artificial grammar learning. Psychological Bulletin 133:227-44. [aBRN]

Pratte, M. S. \& Rouder, J. N. (2009) A task-difficulty artifact in subliminal priming. Attention, Perception \& Psychophysics 71:1276-83. [aBRN] 
Ramsøy, T. Z. \& Overgaard, M. (2004) Introspection and subliminal perception. Phenomenology and the Cognitive Sciences 3:1-23. [aBRN]

Rees, G., Frith, C. D. \& Lavie, N. (1997) Modulating irrelevant motion perception by varying attentional load in an unrelated task. Science 278:1616-19. [aBRN]

Reilly, B. A. \& Doherty, M. E. (1989) A note on the assessment of self-insight in judgment research. Organizational Behavior and Human Decision Processes 44:123-31. [aBRN]

Reilly, B. A. \& Doherty, M. E. (1992) The assessment of self-insight in judgment policies. Organizational Behavior and Human Decision Processes 53:285309. [aBRN]

Reingold, E. M. \& Merikle, P. M. (1988) Using direct and indirect measures to study perception without awareness. Perception \& Psychophysics 44:563-75. [aBRN]

Renkewitz, F., Fuchs, H. \& Fiedler, S. (2011) Is there evidence of publication bias in JDM research? Judgment and Decision Making 6:870-81. [aBRN]

Rey, A., Goldstein, R. M. \& Perruchet, P. (2009) Does unconscious thought improve complex decision making? Psychological Research 73:372-79. [aBRN]

Richardson, D. C., Spivey, M. J. \& Hoover, M. A. (2009) How to influence choice by monitoring gaze. In: Proceedings of the 31st Annual Conference of the Cognitive Science Society, ed. N. Taatgen, H. van Rijn, J. Nerbonne \& L. Schomaker, p. 2244. Cognitive Science Society. [aBRN]

Rolison, J. J., Evans, J. St. B. T., Walsh, C. R. \& Dennis, I. (2011) The role of working memory capacity in multiple-cue probability learning. Quarterly Journal of Experimental Psychology 64:1494-514. [aBRN]

Rouder, J. N., Morey, R. D., Speckman, P. L. \& Pratte, M. S. (2007) Detecting chance: A solution to the null sensitivity problem in subliminal priming. Psychonomic Bulletin \& Review 14:597-605. [aBRN]

Shanks, D. R. (2006) Complex choices better made unconsciously? Science 313:760. [aBRN]

Shanks, D. R. \& St. John, M. F. (1994) Characteristics of dissociable human learning systems. Behavioral and Brain Sciences 17:367-447. [aBRN]

Shanteau, J. (1992) Competence in experts: The role of task characteristics. Organizational Behavior and Human Decision Processes 53:252-66. [aBRN]

Simon, H. A. (1992) What is an explanation of behavior? Psychological Science 3:150-61. [aBRN]

Simmons, J. P., Nelson, L. D. \& Simonsohn, U. (2011) False-positive psychology: undisclosed flexibility in data collection and analysis allows presenting anything as significant Psychological Science 22: 1359-66. [aBRN]

Slovic, P., Fleissner, D. \& Bauman, W. S. (1972) Analyzing the use of information in investment decision making: A methodological proposal. Journal of Business 45:283-301. [aBRN]

Slovic, P. \& Lichtenstein, S. (1971) Comparison of Bayesian and regression approaches to the study of information processing in judgment. Organizational Behaviour and Human Performance 6:649-744. [aBRN]

Smith, E. R. \& Miller, F. D. (1978) Limits on perception of cognitive processes: A reply to Nisbett and Wilson. Psychological Review 85:355-62. [aBRN]

Speekenbrink, M. \& Shanks, D. R. (2010) Learning in a changing environment. Journal of Experimental Psychology: General 139:266-98. [aBRN] 
Strick, M., Dijksterhuis, A., Bos, M. W., Sjoerdsma, A., van Baaren, R. B. \& Nordgren, L. F. (2011) A meta-analysis on unconscious thought effects. Social Cognition 29:738-62. [aBRN]

Strick, M., Dijksterhuis, A. \& van Baaren, R. (2010) Unconscious-thought effects take place off-line, not on-line. Psychological Science 21:484-88. [aBRN]

Surber, C. F. (1985) Measuring the importance of information in judgment: Individual differences in weighting ability and effort. Organizational Behavior and Human Decision Processes 35:156-78. [aBRN]

Thorsteinson, T. J. \& Withrow, S. (2009) Does unconscious thought outperform conscious thought on complex decisions? A further examination. Judgment and Decision Making 4:235-47. [aBRN]

Tomb, I., Hauser, M., Deldin, P. \& Caramazza, A. (2002) Do somatic markers mediate decisions on the gambling task? Nature Neuroscience 5:1103-104. [aBRN]

Trevena, J. A. \& Miller, J. (2002) Cortical movement preparation before and after a conscious decision to move. Consciousness and Cognition 11:162-90. [aBRN]

Uhlmann, E. L., Pizarro, D. A. \& Bloom, P. (2008) Varieties of social cognition. Journal for the Theory of Social Behaviour 38:293-322. [aBRN]

Usher, M., Russo, Z., Weyers, M., Brauner, R. \& Zakay, D. (2011) The impact of the mode of thought in complex decisions: Intuitive decisions are better. Frontiers in Psychology 2:1-13. [aBRN]

Vrieze, S. I. \& Grove, W. M. (2009) Survey on the use of clinical and mechanical prediction methods in clinical psychology. Professional Psychology: Research and Practice 40:525-31. [aBRN]

Wagenmakers, E.-J., Wetzels, R., Borsboom, D. \& van der Maas, H. L. J. (2011) Why psychologists must change the way they analyze their data: The case of psi. Journal of Personality and Social Psychology 100:432-36. [aBRN]

Wagar, B. M. \& Dixon, M. (2006) Affective guidance in the Iowa Gambling Task. Cognitive Affective \& Behavioral Neuroscience 6:277-90. [aBRN]

Waroquier, L., Marchiori, D., Klein, O. \& Cleeremans, A. (2010) Is it better to think unconsciously or to trust your first impression? A reassessment of unconscious thought theory. Social Psychological and Personality Science 1:111-18. [aBRN]

Wegner, D. M. (2004) Précis of The illusion of conscious will. Behavioral and Brain Sciences 27:649-92. [aBRN]

Wegner, D. M., Sparrow, B. \& Winerman, L. (2004) Vicarious agency: Experiencing control over the movements of others. Journal of Personality and Social Psychology 86:838-48. [aBRN]

Weisberg, R. W. (2006) Creativity: Understanding innovation in problem solving, science, invention, and the arts. Wiley. [aBRN]

Weiskrantz, L. (1986) Blindsight: A case study and implications. Oxford University Press. [aBRN]

Weiskrantz, L. (2009) Is blindsight just degraded normal vision? Experimental Brain Research 192:413-16. [aBRN]

White, P. (1980) Limitations on verbal reports of internal events: A refutation of Nisbett and Wilson and of Bem. Psychological Review 87:105-12. [aBRN]

White, P. A. (1988) Knowing more about what we can tell: "Introspective access" and causal report accuracy 10 years later. British Journal of Psychology 79:13-45. [aBRN] 
White, P. A. (1989) Evidence for the use of information about internal events to improve the accuracy of causal reports. British Journal of Psychology 80:37582. [aBRN]

Wilson, T. D. (2002) Strangers to ourselves: Discovering the adaptive unconscious. Belknap Press. [aBRN]

Wilson, T. D. \& Nisbett, R. E. (1978) The accuracy of verbal reports about the effects of stimuli on evaluations and behavior. Social Psychology 41:118-31. [aBRN]

Wilson, T. D. \& Schooler, J. W. (1991) Thinking too much: Introspection can reduce the quality of preferences and decisions. Journal of Personality and Social Psychology 60:181-92. [aBRN]

Winkielman, P., Berridge, K. C. \& Wilbarger, J. L. (2005) Unconscious affective reactions to masked happy versus angry faces influence consumption behavior and judgments of value. Personality and Social Psychology Bulletin 31:12135. [aBRN]

Wright, P. \& Rip, P. D. (1981) Retrospective reports on the causes of decisions. Journal of Personality and Social Psychology 40:601-14. [aBRN]

Zhong, C.-B. \& Liljenquist, K. (2006) Washing away your sins: Threatened morality and physical cleansing. Science 313:1451-52. [aBRN] 